\title{
Y ASÍ SE DICE...: LOS EJEMPLOS Y LAS NOTAS DE USO EN LOS DICCIONARIOS ACADÉMICOS (1726-1852)*
}

\author{
Y ASÍ SE DICE...: EXAMPLES AND USAGE NOTES IN THE ACADEMIC \\ DICTIONARIES (1726-1852)
}

\author{
M. a Ángeles Blanco IzQuierdo, Gloria Clavería Nadal
}

Centro de Estudios de la RAE, Universidad Autónoma de Barcelona

Recibido: $14 / 02 / 2019$

Aceptado: 15/04/2019

\begin{abstract}
Resumen
Existen en el primer diccionario académico (1726-1739) múltiples ejemplos y notas de uso que acompañan a las tan características autoridades. En este trabajo se toma como punto de partida la presencia de este tipo de información en el Diccionario de autoridades y se traza su evolución hasta la décima edición del diccionario usual, publicada en 1852, pasando, en primer lugar, por la segunda edición del Diccionario de autoridades (1770) y, en segundo lugar, por la transformación de esta obra en un compendio en un solo volumen del que se eliminan las citas (DRAE 1780). El análisis de cada una de las ediciones estudiadas permite seguir el devenir de un tipo de información lexicográfica que enriquece la definición y contribuye al valor codificador de la obra, pero que no está exenta de las asistematicidades propias de un diccionario cuya confección es plural y cuya revisión se hace por etapas.

PALABRAS CLAVE: Lexicografía, diccionarios académicos, siglo XIX, ejemplos, uso.
\end{abstract}

\begin{abstract}
In the first edition of the dictionary by the Real Academia Española (1726-1739) many examples and usage notes can be found alongside with the renowned quotations (autoridades). In this paper, the presence of this kind of information in the Diccionario de autoridades is taken as a starting point to track its evolution until the tenth edition of the dictionary published in 1852. First, the second edition of the Diccionario de autoridades (1770) is analyzed and, secondly, the transformation of this work into a single compendium in which the quotations were removed (DRAE 1780) is examined. The study of every edition of the dictionary enables to establish the progression of a type of lexicographic information that enhances the definition and that contributes to the encoding value of the dictionary. However, it is not systematic due to its process of elaboration.
\end{abstract}

KEY WORDS: Lexicography, academic dictionaries, nineteenth century, examples, use.

\footnotetext{
* Esta investigación ha podido desarrollarse gracias a la ayuda de la DGICYT (FFI2014-51904-P) y al apoyo del Comissionat per Universitats i Recerca de la Generalitat de Catalunya (SGR2017-1251).
}

Para citar este artículo / To cite this article: Blanco Izquierdo, María Ángeles; Clavería Nadal, Gloria (2019). Y así se dice...: los ejemplos y las notas de uso en los diccionarios académicos (1726-1852). Azorín, Dolores; Clavería, Gloria y Jiménez Ríos, Enrique (Eds.): ELUA: El diccionario de la Academia y su tiempo: lexicografia, lengua y sociedad en la primera mitad del siglo XIX, Anexo V, págs. 339-379.

Enlace/Link: http://dx.doi.org/10.14198/ELUA2019.ANEXO5.14 
De acuerdo con Haensch y Omeñaca (2004: 190-191), un diccionario de uso se caracteriza por presentar al menos dos de estos tres elementos: ampliación paradigmática, como la incorporación de sinónimos y antónimos, variantes o palabras de la misma familia; ampliación sintagmática, que informa sobre el uso contextual de las unidades léxicas (información combinatoria, estructura argumental, construcción y régimen, etc.), y recurso a lo que los autores llaman frase-ejemplo.

El presente trabajo se centra en el estudio de la evolución de las notas y los ejemplos de uso que forman parte intrínseca de la información lexicográfica de muchas voces en los diccionarios académicos, un aspecto de la microestructura del diccionario que hasta ahora ha recibido poca atención. Es este uno más de los muchos puntos de partida en la comparación de las sucesivas ediciones del diccionario, pues los ejemplos y notas de uso han formado parte de él desde el Diccionario de autoridades y han permanecido hasta hoy. Se trata de unos elementos que, además de ser interesantes en sí mismos por la información que proporcionan, ayudan a caracterizar y corroborar algunas tendencias generales de las distintas ediciones, y pueden ser útiles para la reconstrucción del modelo de revisión y aumento que aplicaron los académicos.

Este artículo, que es una primera aproximación al tema, parte del Diccionario de autoridades (1726-1739), estableciendo, en primer término, una tipología de la información sobre el uso que esta obra ofrece (epígrafe 1), para centrarse después en el análisis de los cambios relativos a las notas y ejemplos registrados tanto en la segunda edición del Diccionario de autoridades (epígrafe 2) como en las distintas ediciones del diccionario usual hasta mediados del siglo xIX (DRAE 1852) distinguiendo dos etapas, 1780-1803 (epígrafe 3) y 1817-1852 (epígrafe 4), pues se perciben notables modificaciones entre ellas. Queda para más adelante el estudio del devenir de este tipo de información desde la segunda parte del siglo XIX hasta la última edición del diccionario académico (DLE 2014). El análisis aborda tanto las transformaciones de la información sobre el uso en los lemas heredados de otras ediciones (enmienda) como la presencia de notas y ejemplos en los nuevos lemas que se incorporan en la primera mitad del XIX (aumento) ${ }^{1}$. Interesa en este último caso observar si el estilo de la definición mantiene la atención al uso, tan presente, como veremos, en el discurso lexicográfico del Diccionario de autoridades.

\section{LA INFORMACIÓN SOBRE EL USO EN EL DICCIONARIO DE AUTORIDADES (1723-1739)}

El Diccionario de autoridades, punto de partida de la lexicografía académica y también de nuestra investigación, requiere un estudio pormenorizado, pues, en la materia que nos ocupa, se configura como una obra lexicográfica especialmente compleja. Las alusiones al uso de las voces dentro del diccionario son muy abundantes y de diversa índole. Se trata de una información

\footnotetext{
1 Para desarrollar esta investigación, se han realizado unas calas en el Diccionario de autoridades y se ha seguido la evolución de las entradas con notas de uso a lo largo de todas las ediciones. Además, se han analizado los suplementos de los $D R A E 1780$ y 1783 , y la letra $D$ del $D R A E 1791$. Se ha tenido en cuenta el aumento de lemas de los DRAE 1817-1852 a partir de los datos obtenidos en el proyecto "Historia interna del Diccionario de la lengua castellana de la Real Academia Española en el siglo XIX (1817-1852)" y, para el estudio de las modificaciones en la microestructura, se han realizado diversas calas en las ediciones estudiadas. Se ha utilizado el NTLLE para todas las consultas, por lo que, para las referencias bibliográficas de los diccionarios, remitimos a esta obra.
} 
heterogénea y en permanente evolución por los cambios introducidos en las sucesivas ediciones del diccionario a partir de 1770. No hay que olvidar, además, que uno de los fundamentos de esta obra se encuentra en los textos citados que ilustran el uso de las voces, de ahí que para designarla se haya popularizado el título de Diccionario de autoridades, lo que manifiesta que el uso lingüístico tenía una presencia muy notable en el primer diccionario académico.

\subsection{Tipología de la información sobre el uso en Autoridades}

Una cala en el primer diccionario académico muestra una amplia tipología de información sobre el uso complementando las definiciones.

\subsubsection{Notas que indican restricciones en el uso}

Dentro del propio discurso lexicográfico hay, por una parte, referencias que aportan alguna limitación de empleo. Estas notas señalan el lugar, la época, el registro, el contexto comunicativo o el área técnica en los que se emplea una unidad léxica o alguna de sus acepciones. Son ejemplos de notas con información diatópica, que dan cuenta de restricciones del uso de una voz a determinadas áreas, entradas como las correspondientes a albalá y solla ${ }^{2}$.

ALBALÁ. s. m. El despacho, licéncia, testimónio authéntico, escritúra, carta de pago, ù otro instrumento semejante, por donde consta alguna cosa para la fé pública en Puertos, Aduánas, \&c. Es voz de poco uso en Castilla. En Valencia y Aragón se conserva y usa comunmente $^{3} \ldots$

SOLLA. s. f. Pescado. Lo mismo que Suela. Es voz Provincial de Galicia.

Se ofrece información de carácter diacrónico, sobre la vigencia de uso del lema, en entradas como cadaveroso y tortedad.

CADAVEROSO, SA. adj. Lo mismo que Cadavérico. Voz Latína que usan voluntariamente algunos Médicos para denotar lo desfigurado del rostro; aunque oy dicen mas comunmente Cadavérico. Lat. Cadaverosus, a, um.

TORTEDAD. s. f. Obliquidád, ò corvadúra de alguna cosa. Trahe esta vox Nebrixa en su Vocabulario; pero yá no tiene uso. Lat. Obliquitas. Curvitas.

Incorporan información de tipo estilístico, sobre el registro o el contexto comunicativo en el que las voces se emplean o sobre la intención del hablante al usarlas, entradas como langaruto, fumífero o arrugarse.

2 Todas las entradas de este apartado están tomadas del Diccionario de autoridades, 1726-1739. Se respetan los usos gráficos y ortográficos del original. También se respeta la distinción entre la mayúscula y la versalita para los lemas y los sublemas, presente en el diccionario hasta el DRAE 1822. Las entradas extensas no se reproducen por completo si no es estrictamente necesario para los objetivos de este trabajo. Las supresiones se marcan con puntos suspensivos, encerrados entre corchetes si la parte suprimida se encuentra en el interior del artículo. Por último, se reproducen en un mismo párrafo y separados por barras los versos de las citas, que en el original se sitúan en párrafos distintos.

3 La negrita con la que se destacan determinados fragmentos de las entradas del diccionario es siempre nuestra. 
LANGARUTO, TA. adj. que se aplica al que es de estatúra mui alta, flaco de cuerpo y de piernas mui delgadas. Es voz baxa, y la trahe Covarr. en su Thesoro. Lat. Nimis longus.

FUMIFERO, RA. adj. Lo que arroja ù despide de sí humo. Es voz Poética. Lat. Fumifer. Lop. Dorot. f. 115. Virgilio dixo, que arrojaba Caco de la boca una fumifera noche.

ARRUGARSE. Translaticiamente se usa por lo mismo que morir: y assi del que falleció se dice que se arrugó. Es phrase jocósa, y del estílo familiar. Lat. Obire.

Finalmente, la restricción de una voz a determinada área técnica se marca con notas como las de abades y sagital.

ABADES. s. m. Es lo mismo que Abadéjo en el significado de Cantháridas, de cuyo término usan los Albéitares. Vease Abadéjo. Lat. Canthárides.

SAGITAL. adj. de una term. Cosa perteneciente à saéta, ò que tiene su semejanza. Usase en la Anatomía. Lat. Sagittalis, e. MART. Anat. Complet. Lecc. 10. En aquel sitio donde se junta la sutúra coronál con la sagitál.

Este tipo de referencias aparecen en el Diccionario de autoridades situadas tras la definición, pero formando parte del discurso lexicográfico. Desde la segunda edición de Autoridades se iniciará un proceso por el que estas informaciones se homogeneizarán y codificarán por medio de abreviaturas antepuestas a la definición (Pascual Fernández 2009) ${ }^{4}$. Como no proporcionan información sintagmática ni paradigmática, quedarán fuera de los límites de este trabajo.

\subsubsection{Notas que describen el uso vigente}

Otro grupo de notas describe propiedades lingüísticas del lema asociadas al uso. No nos referimos aquí, por tanto, a la información lingüística sin más (etimología, caracterización gramatical — categoría, conjugación, etc.-), sino a las observaciones gráficas, fónicas, morfológicas, sintácticas o léxico-semánticas que constituyen notas de uso. Presentan, asimismo, una amplia tipología en el primer diccionario académico, como puede observarse en los ejemplos siguientes.

a) Notas de carácter gráfico o fónico, que hacen referencia frecuentemente a variantes formales, como las que se encuentran en las entradas albañar o xo.

ALBAÑAR. s. m. El desaguadéro, canál, ò conducto que hai en las casas, Ciudádes y Pueblos para expeler y limpiar las immundicias. Algunos escriben y pronuncian esta voz con $l$ en lugar de la $r$, diciendo Albañál; pero su mas comun pronunciación es con ella...

XO. Interjección. Lo mismo que Jo, ò Cho. Algunos la escriben assi, y pronuncian la $\boldsymbol{x}$ suavemente.

4 Así, la adscripción técnica de la voz abades pasa a expresarse de la siguiente forma en Autoridades 1770: “ABADES. s. m. plur. (Albeyt.) Lo mismo que abadejo en el significado de cantárida. Cantharides". 
Estas notas pueden estar asociadas a información de carácter diacrónico, al contraponer estadios antiguos del idioma con la situación hodierna.

EFECTO. s. m. Lo que se sigue de alguna cáusa, y lo que ella prodúce. Es tomado del Latino Effectus, que significa esto mismo. En lo antiguo se usaba mucho sin la $c$ diciendo Efeto; pero oy comunmente se escribe con ella por ser conforme à su origen, y porque assi se pronuncia...

b) Notas de carácter morfológico, como las referidas al género y al número en arena y caroca, respectivamente, o la que introduce una referencia al derivado enalbardar en el lema albardar.

ARENA. s. f. Tierra menúda como de naturaleza de piedra. Viene del Latino Arena. Usase de esta voz promiscuamente con los artículos masculino y femenino. Lat. Arena. Sabulum. COMEND. sob. las 300. fol. 62. Los cuerpos muertos de los que assi mueren se llaman carne mómia, y el aréna que los cubre aréna mómia. GONG. Poliphem. Oct. 44. Pisa la aréna que en la aréna adóro.

CAROCA. s. f. La palabra afectada, ò la accion cariñosa con que se tira à engañar, ò lisonjear à alguno, para lograr del lo que se quiere. Usase mas comunmente en plural. Lat. Allectamentum. Delinimentum. Lenocinium. Lop. Philom. fol. 113. Quando se representan las carócas / En versos, sino bárbaros, mestizos.

ALBARDAR. v. a. Poner la albarda à qualquiera béstia. Usase casi siempre de este verbo con la preposición en, diciendo Enalbardar. Vease. Lat. Mulum clitellis induere, instruere. Comed. Florin. Scen. 39. fol. 136. Porque tampóco no me tengo por tal que piense de albardarme, sin que dé corcovos.

c) Notas de carácter sintáctico-semántico, que pueden ofrecer información combinatoria, sobre construcción y régimen, etc. Valgan como ejemplo las entradas subirse en zancos, que restringe la combinación de este sustantivo a unos cuantos verbos, y resollar, que da cuenta de la frecuencia con que este verbo es un término de polaridad negativa.

Subirse en zancos. Phrase metaphórica, que significa engreirse, y ensoberbecerse con la buena fortuna, despues de haber medrado con facilidad, y salido de pobreza, y miseria. Usase tambien con otros verbos: como ponerse, estár, y andar, y explica lo mismo. Lat. Supra se efferri. Fortunâ superbire. (s. v. zanco).

RESOLLAR. Se toma tambien por hablar. Usase freqüentemente con la negacion: y assi se dice, No resolló. Lat. Respirare.

d) Por último, el Diccionario de autoridades incluye notas de carácter léxico-semántico. Algunas, como la que figura en chisguete, ofrecen información sinonímica, lo que no es especialmente frecuente. Otras informan sobre el paradigma léxico con el que se combina el lema, como sucede en crespo, que, de acuerdo con la nota, se combinaría propiamente con melena, pelo, barba, cabello..., en lo que hoy se consideraría un contorno lexicográfico no integrado en la definición. 
CHISGUETE. s. m. Corta cantidad de vino, que se bebe por vasija estrecha de boca, como calabaza ò botija. Otros lo llaman chispo. Lat. Vini haustus, us.

CRESPO, PA. adj. Rizo, ò ensortijado. Propriamente se dice del cabello. Viene del Latino Crispus, que significa esto mismo. Calist. y MeliB. Act. 15. Qué tiene bueno, los cabellos crespos y la cara acuchillada?...

En resumen: con las notas a las que se refiere este apartado, que llamaremos en este trabajo notas de uso, se enriquece el artículo lexicográfico tanto con información paradigmática — la relativa a variantes y sinónimos - como con información sintagmática, que da cuenta de las agrupaciones características, la estructura argumental o la construcción del lema.

\subsubsection{Ejemplos que ilustran el uso}

Además de todas las informaciones mencionadas en los epígrafes anteriores, el primer diccionario académico incluye, en ocasiones, ejemplos como parte de la información lexicográfica. Tal como ha señalado Rey (1995: 96), “le concept d'exemple, pris généralement, s'inscrit dans une longue tradition, essentiellement rhétorique et en partie juridique" y este principio, como ha demostrado José Manuel Blecua (2006), está bien presente en la concepción lexicográfica del Diccionario de autoridades y sus textos (cfr. Lara 1992: 44). En los principios que rigen la obra, como se expone claramente en el prólogo, se establece una diferencia entre los textos con valor de autoridad y los textos destinados a la comprobación. Los primeros son aducidos "[c] omo basa y fundamento de este Diccionario", pues se extraen de "los Autóres que ha parecido à la Académia han tratado la Léngua Españóla con la mayor propriedád y elegáncia: conociendose por ellos su buen juício, claridád y proporción, con cuyas autoridades están afianzadas las voces" (tomo I, II). Estos textos se encuentran recogidos en la "Lista de los autores elegidos por la Real Académia Españóla, para el uso de las voces y modos de hablar, que han de explicarse en el Diccionario de la Léngua Castellana, repartidos en diferentes clases, segun los tiempos en que se escribieron, y separados los de prosa, y los de verso" (tomo I, LXXXV) ${ }^{5}$. Existen, además, los textos utilizados como comprobación. La diferente consideración teórico-práctica de unos y otros queda claramente establecida en los preliminares del diccionario:

Las citas de los Autóres para comprobación de las voces, en unas se ponen para autoridád, y en otras para exemplo, como las voces que no están en uso, y el olvído las ha desterrado de la Léngua, de calidád que se haría extraño y reparable el que hablasse en voces Castellanas antíguas, que yá no se practican; pero aunque la Académia (como se ha dicho) ha elegido los Autóres que la han parecido haver tratado la Léngua con mayor gallardía y elegáncia, no por esta razón se dexan de citar otros, para comprobar la naturaleza de la voz, porque se halla en Autór nacionál, sin que en estas voces sea su intento calificar la autoridád por precissión del uso, sino por afianzar la voz (tomo I, V).

Junto a los ejemplos extraídos de los textos, que hacen del Diccionario de autoridades una obra lexicográfica fundamentalmente filológica (Zgusta 1971: 265), es posible encon-

5 La evolución y conformación de estas listas puede encontrarse en Freixas (2010: 112 y ss.). 
trar en el primer diccionario académico ilustraciones del empleo de las voces sin que figure ningún tipo de identificación de la procedencia del ejemplo, un contexto típico que muestra cómo se utilizan las unidades léxicas en el discurso. Son, pues, ejemplos creados ad hoc por los redactores según el modelo del diccionario de la Academia Francesa (cfr. Pascual Fernández 2013: 163-163). Freixas (2010: 268) considera que esos ejemplos intentan "reproducir los usos vigentes en la lengua de la época contemporánea a la redacción del Diccionario de Autoridades" y los interpreta como próximos a la lengua oral (2010: 327 y ss.). Si bien es cierto que en algunos casos el ejemplo no concurre con ninguna cita textual (cfr. las voces filili, pamplina 'cosa de poca entidad', parola 'conversación en asunto de poca entidad' y valiente 'grande o excesivo' citadas por Álvarez de Miranda 2005), su uso es mucho más amplio, pues menudean los ejemplos inventados en las entradas polisémicas (cfr. Atkins y Rundell 2008: 454) y pueden concurrir con los procedentes de los textos escritos (cfr. calle de hombres, decir 'llamar', verdad 'expresión clara', etc.). Pensamos, de hecho, que el ejemplo forma parte de la atención al uso y que en múltiples ocasiones adopta una función completamente diferenciada de los textos; en él, se destacan de un modo eminentemente pedagógico y modélico las condiciones básicas y analógicas de ciertas particularidades lingüísticas poniendo de relieve su tipicidad a través de la ilustración de aspectos muy concretos, de ahí que los ejemplos sean frecuentemente fragmentos reducidos (Dubois y Dubois 1971, Zgusta 1971: 267, Martin 1989, Rey-Debove 1992, Atkins y Rundell 2008: 459-460).

Este tipo de ejemplificación responde a los principios básicos de la ilustración lexicográfica, de modo que suelen ser frases completas de estructuras simples (v. infra sino) o unidades sintagmáticas mínimas (v. infra dar o abacial); pueden también comportar diversos tipos de "neutralización" con eliminación de marcas flexivas ("dar de azotes" en dar), referencias genéricas para los sujetos ("fulano le dixo dos verdades" en verdad) y enumeración de coocurrencias sintácticas ("dar de azotes, de golpes, de palos de heridas, de estocadas" en el ejemplo de dar) (Rey-Debove 1971: 303-307, Garriga 2002: 141-142). A diferencia de las autoridades y los textos, que ocupan un puesto bien definido en la entrada, los ejemplos se integran en el discurso lexicográfico con unas fórmulas determinadas (epígrafe 1.2).

Estas muestras prototípicas de lengua aparecen tanto en palabras de significado léxico como en palabras de significado gramatical. Unas se introducen para ilustrar una característica gramatical del lema en una determinada acepción; en estos casos, suelen combinarse con las observaciones lingüísticas de carácter gramatical mencionadas antes (notas de uso). Esta concurrencia de nota y ejemplo da lugar a artículos idóneos tanto para la descodificación como para la codificación de enunciados. Así, en el lema sino se hace evidente la construcción en la que interviene esta conjunción y se la caracteriza como término de polaridad negativa.

Sino. Se usa assimismo para distinguir una cosa de otra contraponiendolas, y entonces siempre le precede proposicion negativa; verbigracia, No es blanco, sino pardo. Lat. Imò.

Por su parte, en dar los ejemplos ilustran características sintáctico-semánticas del lema: la posibilidad de construirlo como verbo intransitivo o transitivo y su combinación con sustantivos que indican "el instrumento de la pena o castigo".

DAR. Vale tambien cascár, golpeár, apaleár, castigár, herir: como Dár de azótes, de golpes, de palos, de heridas, de estocadas. Y tambien se puede usar poniendo el instru- 
mento de la pena o castigo en acusativo: como Dár azótes, \&c. Lat. Percutere. Tundere. Ferire. Quev. Tacañ. cap. 20. Cierra conmigo uno de los dos... y con un garróte dame dos palos en las piernas y derribame en el suelo, y llega el otro y dame un trasquilón de oréja á oréja.

Otros ejemplos ilustran una acepción, es decir, son un auxiliar de la definición lexicográfica. Contribuyen, pues, a que se entiendan los significados, amén de proporcionar agrupaciones sintagmáticas frecuentes o contextos típicos de aparición de la voz.

ABACIAL. adj. de una terminación. Cosa que pertenéce al Abád: y assi se dice la Celda Abaciál, \&c. Es tomado del Latino Abbatialis.

Este tipo de ejemplos son casi imprescindibles para entender las definiciones de las palabras de significado gramatical, como que, y de los verbos soporte, como hacer, cuya definición, en la acepción que se reproduce, se acompaña de una amplísima enumeración de agrupaciones sintagmáticas que la aclaran.

Que. Se usa tambien distribuyendo los extrémos contrarios de una oración: como Que llueva, que no llueva. Lat. Necne. vel Distributivè.

HACER. Junto con algunos nombres significa actual exercicio de los verbos que se forman de los tales nombres à que corresponden: como Hacer estimacion vale estimar, hacer gastos, gastar: hacer burla, burlarse, \&c. Y otras veces reducir una cosa ò ponerla en el estádo de lo que significan los nombres: como Hacer pedazos, trozos, migajas, \&c. Otras veces vale usar ò valerse de lo que los nombres significan: como Hacer señas, gestos, figuras, \&c.

Igualmente útil es la presencia de ejemplos como complemento de la definición en voces especialmente polisémicas como entrar, la mitad de cuyas veintidós acepciones contienen ejemplos inventados, o el propio verbo hacer, que como lema simple cuenta con treinta y cuatro acepciones, de las cuales solo siete carecen de un ejemplo inventado, frente a las veintisiete que presentan este tipo de ejemplificación.

\subsection{La información sobre el uso en el discurso lexicográfico}

El discurso lexicográfico del Diccionario de autoridades emplea de forma recurrente ciertas fórmulas para enlazar la definición con las observaciones sobre el uso descritas en 1.1.2 y 1.1.3. En el ámbito de la ampliación paradigmática, los sinónimos suelen introducirse con fórmulas como otros lo llaman, comúnmente se llama, en algunas partes se llama o alguna variante; así puede observarse en el lema chisguete antes reproducido o en frisoles, entrada rica en información sinonímica que utiliza dos de estas fórmulas.

FRISOLES. s. m. Legumbre que comunmente se llama Judías ò Judihuélos. En algunas partes los llaman Frixoles. Lat. Phaseolus, li. LAG. Diosc. lib. 2. cap. 99. Todas las señales de la Smilace hortense conspiran en los Phasiolos de Italia; llamados Judihuélos en nuestra España, y tambien frísoles. 
Para las variantes gráficas, fónicas o morfológicas se emplean fórmulas como muchos o algunos escriben/pronuncian..., en algunas partes se usa..., oy se escribe... (véanse entradas como albañar o efecto), y esta información suele enriquecerse con explicaciones de variado tipo, como alusiones etimológicas (academia) o normativas (zar).

ACADEMIA. s. f. Lugar en Athénas donde Platon enseñaba la Philosophía. Es voz Griega, por cuya razon algunos la pronuncian haciendo la $i$ larga, conforme su origen. Lat. Académia.

ZAR. s. m. El Príncipe Soberano, y Dominante de Moscovia. Muchos escriben este nombre con $c$ antes de la $z$, que es como lo escriben los Moscovitas; pero respecto de la dificultad de su pronunciacion, y que algunos le escriben con $z$ sola, se fija aquí...

En cuanto a las notas de uso que introducen información sintagmática, el verbo característico es usar, aplicado específicamente al uso lingüístico, acompañado de algún elemento relativo a la frecuencia. Estas son algunas de las fórmulas más documentadas en Autoridades:

\begin{tabular}{l|l} 
úsase / se usa / usado & $\begin{array}{l}\text { solo... } \\
\text { también... } \\
\text { frecuentemente... } \\
\text { comúnmente... } \\
\text { regularmente... } \\
\text { más frecuentemente... } \\
\text { más comúnmente... } \\
\text { muchas veces... } \\
\text { las más veces... } \\
\text { casi siempre... } \\
\text { siempre... }\end{array} \mid$ \\
\end{tabular}

suélese usar / se suele usar...

de ordinario se usa...

comúnmente se junta...

usábase...

La forma del verbo en imperfecto, usábase, incorpora, además, información diacrónica, como ilustra este ejemplo:

INSULA. s. f. Lo mismo que Isla, que es como oy se dice. Usabase mucho en lo antiguo, especialmente en los libros de Caballerías. Es voz puramente Latina Insula. AmAD. lib. 4. cap. 16. Ellos respondieron que allí venía la Reina Briolanja, que passaba a la ínsula firme.

Algunas notas relativas a la combinatoria de las palabras - justo las que hoy denominamos contorno lexicográfico - emplean como fórmulas introductorias se dice de..., se aplica a..., que han figurado en el diccionario hasta su vigesimoprimera edición (DRAE 1992). 
Finalmente, el verbo característico para introducir los ejemplos es decir, normalmente precedido de y así. Y así se dice ${ }^{6}$ rivaliza con como a la hora de introducir ejemplificaciones. Estas son las fórmulas más documentadas en Autoridades:

como (por ejemplo)

verbigracia (muy poco frecuente, y todos los ejemplos del tomo vi)

\begin{tabular}{l|l}
$y$ asi & $\begin{array}{l}\text { se dice } \\
\text { decimos } \\
\text { dicen } \\
\text { comúnmente se dice } \\
\text { se suele decir }\end{array}$
\end{tabular}

y en este sentido se dice...

en fuerza de lo cual decimos...

en fuerza de esto se dice...

úsase en la frase...

En la primera edición de Autoridades hay cierta uniformidad en las fórmulas que introducen las notas y ejemplos, si bien se está lejos del uso de las fórmulas fijas a las que tenderá la lexicografía posterior. No hay, sin embargo, un recurso tipográfico que resalte los ejemplos dentro del artículo, bien delimitados por sus fórmulas introductorias. Además, la tendencia a destacar en cursiva el lema ejemplificado cuando se citan las autoridades (cfr. entendederas) es rara en los ejemplos de uso, aunque se atestigua en algunos (cfr. sino). En su lugar, suele usarse la mayúscula inicial, que también marca los sinónimos o variantes mencionados dentro del artículo (cfr. abacial, dar, frisoles, hacer, que).

\subsection{El Diccionario de autoridades como un diccionario de uso}

La tipología expuesta en el apartado 1.1 puede condensarse en el siguiente esquema:

- Notas que indican restricciones en el uso:

- restricciones diatópicas

- restricciones diacrónicas

- restricciones estilísticas

- restricciones a un área profesional

- Notas de tipo lingüístico que describen el uso vigente:

- notas de carácter gráfico o fónico

- notas de carácter morfológico

- notas de carácter sintáctico-semántico

- notas de carácter léxico-semántico

6 Quemada (1968: 511) menciona una fórmula similar, on dit, para introducir los ejemplos en el primer diccionario de la Academia Francesa. 
- Ejemplos que ilustran el uso:

- para ilustrar una propiedad gramatical del lema

- para ilustrar una acepción

A la vista de este cuadro, queda patente el intento por parte de los primeros académicos de recoger abundante información sobre el uso real en el momento en el que se elabora el diccionario. Por un lado, advirtiendo de las restricciones que tienen en su empleo las palabras y acepciones que se registran, circunscribiéndolas a un ámbito cronológico, técnico, geográfico, etc., concreto. Por otro, dando cuenta de variantes y de sinónimos, y, lo que aquí más interesa, incorporando pautas sobre el uso contextual de las unidades léxicas del diccionario mediante las notas gramaticales y los ejemplos que acompañan a la definición lexicográfica —o se integran en ella—: ya informando sobre la forma flexiva en la que el lema se usa preferentemente (plural, adjetivo usado como sustantivo masculino o femenino, etc.), ya sobre las combinaciones en las que participa (sustantivos a los que se aplica un adjetivo, sustantivos con los que se combina un verbo, etc.), las construcciones que requiere (régimen, estructura argumental), etc. Esta forma de proceder acerca el Diccionario de autoridades a un diccionario codificador.

Las notas y ejemplos que se han mostrado en los apartados 1.1.2 y 1.1.3 son buena muestra de la presencia en el primer Diccionario de autoridades de los tres elementos característicos de un diccionario de uso descritos por Haensch y Omeñaca (2004: 190191). Notas y ejemplos no se introducen de manera sistemática, pero sí constituyen una información frecuente y siempre oportuna, lo que permite adscribir en cierto modo el primer diccionario académico a un diccionario de uso. A todo ello hay que unir el carácter ilustrador de las autoridades, con lo que las informaciones sobre el empleo de las voces quedan, si cabe, mayormente potenciadas.

\section{EVOLUCIÓN DE LAS NOTAS Y EJEMPLOS. EL DICCIONARIO DE AUTORI- DADES DE 1770}

La segunda edición del Diccionario de autoridades, emprendida desde muy pronto, dio como resultado la publicación en 1770 del primer tomo de la nueva edición con las letras $A$ y $B$ (Seco 1991 [2003]: 237-240). Las características del diccionario continuaban siendo las mismas y la revisión comportó cambios en la nomenclatura y también modificaciones de la definición y de otros aspectos (Garrido Moraga 1987, 1992; Álvarez de Miranda 2000: 45-47). Una importante novedad es que empiezan a utilizarse abreviaturas para la codificación de informaciones de variado tipo, con lo que el discurso lexicográfico empieza a cambiar ostensiblemente. El empleo de las abreviaturas se irá consolidando de manera progresiva en las distintas ediciones del diccionario académico: si en el primer Autoridades (tomo I, Lxxxx) solo se usaron abreviaturas de carácter gramatical, en 1770 se amplían las notas que implican informaciones gramaticales (por ejemplo, $A d v$. lug., Loc., Mod. adv., Núm.) y las que indican restricciones en el uso, sobre todo para marcar el ámbito de especialidad (más de cuarenta abreviaturas), aunque no faltan las relativas a la variación estilística (Bax., Fam., Festiv., Irónic., Metáf., Poét., Vulg.), a la vigencia 
(Antiq., Poc. us., R. ${ }^{7}$ ) y a las geolocalizaciones (Provinc.). Se incorpora asimismo la abreviatura $v$. (véase) como fórmula de remisión y, aunque no figura en la lista de abreviaturas (Autoridades 1770: LXI-LXII), se consolida la presencia de v. g. (verbigracia) para la introducción de ejemplos.

La voluntad sintetizadora perseguida al redactar esta edición, a la que se refiere Garrido Moraga (1992: 269), se manifiesta, en el ámbito de las notas de uso, en la tendencia a presentar de manera más abreviada las variantes, evitándose a veces reproducir la definición en la entrada de la forma no preferida. Este modo de proceder queda declarado en el prólogo de la segunda edición de Autoridades (Muñoz 2018: 205) y puede observarse en la práctica en el cambio sufrido por albardar. La definición seguida de la nota paradigmática va evolucionando, pues, hacia la remisión.

\begin{tabular}{|l|l|}
\hline \multicolumn{1}{|c|}{ Diccionario de autoridades } & \multicolumn{1}{|c|}{ Diccionario de autoridades 1770} \\
\hline $\begin{array}{l}\text { ALBARDAR. v. a. Poner la albarda à qualquiera } \\
\text { béstia. Usase casi siempre de este verbo con la } \\
\text { preposición en, diciendo Enalbardar. Vease... }\end{array}$ & $\begin{array}{l}\text { ALBARDAR. v. a. Lo mismo que enalbardar, } \\
\text { que es como hoy comunmente se dice... }\end{array}$ \\
\hline $\begin{array}{l}\text { ENALBARDAR. v. a. Echar ò poner la albarda à } \\
\text { las bestias, aparejarlas con la albarda ò albardón, } \\
\text { y demás cosas, para servirse de ellas... }\end{array}$ & - \\
\hline
\end{tabular}

Por otro lado, las notas que incorporan variantes o sinónimos van sometiéndose a un proceso paulatino de formalización, como en el ejemplo anterior, en el que se reemplaza "úsase casi siempre de este verbo con la preposición en diciendo Enalbardar. Véase" por "lo mismo que enalbardar, que es como hoy comunmente se dice". En esta misma línea de formalización y simplificación, lo mismo que y las fórmulas equivalentes utilizadas para vincular variantes van dejando paso a simples remisiones introducidas por véase o su abreviatura, como ocurre en albañar, en cuya entrada se mencionaba la variante albañal, algo que se sistematiza en dos entradas con remisión de albañar a albañal en la segunda edición de Autoridades, en atención al uso más extendido.

\begin{tabular}{|c|c|}
\hline Diccionario de autoridades & Diccionario de autoridades 1770 \\
\hline $\begin{array}{l}\text { ALBAÑAR. s. m. El desaguadéro, canál, ò } \\
\text { conducto que hai en las casas, Ciudádes y } \\
\text { Pueblos para expeler y limpiar las immundicias. } \\
\text { Algunos escriben y pronuncian esta voz con } \boldsymbol{l} \\
\text { en lugar de la } \boldsymbol{r} \text {, diciendo Albañál; pero su mas } \\
\text { comun pronunciación es con ella... }\end{array}$ & $\begin{array}{l}\text { ALBAÑAL. s. m. El canal, ó conducto que hay } \\
\text { en las casas, y en los pueblos para expeler las } \\
\text { inmundicias. En lo antiguo, y hasta de algun } \\
\text { tiempo á esta parte se dixo albañar, pero hoy } \\
\text { la voz comun es albañal... }\end{array}$ \\
\hline- & ALBAÑAR. V. albañal. \\
\hline
\end{tabular}

En cuanto a las notas que introducen información sintagmática, la segunda edición de Autoridades mantiene las fórmulas con el verbo usar más o menos modificadas, las cuales,

7 Abreviatura equivalente a "voz ó frase de raro uso". 
de hecho, se mantienen hasta la actualidad ${ }^{8}$. También en los ejemplos de uso se conservan las fórmulas (preferentemente como o y así se dice, esta última seguida con frecuencia de dos puntos), en 1770 y durante prácticamente todo el siglo XIX, con algunos bailes entre ellas de una edición a otra ${ }^{9}$, como se puede observar en las dos entradas siguientes:

\begin{tabular}{|c|c|}
\hline Diccionario de autoridades & Diccionario de autoridades 1770 \\
\hline $\begin{array}{l}\text { ABACIAL. adj. de una terminación. Cosa } \\
\text { que pertenéce al Abád: y assi se dice la Celda } \\
\text { Abaciál, \&c.... }\end{array}$ & $\begin{array}{l}\text { ABACIAL. adj. de una term. Lo que pertenece al } \\
\text { Abad. como celda abacial, \&c.... }\end{array}$ \\
\hline $\begin{array}{l}\text { ARTE. Se toma por ciéncia algunas veces: } \\
\text { como el curso de artes, esto es de las ciéncias } \\
\text { Metaphysica y Physica. Lat. Ars ingenua, } \\
\text { liberalis. Lop. Comed. La Escolastica zelosa, } \\
\text { jorn. 3. Estos votos habrán sido / de alguna } \\
\text { cáthedra de artes. }\end{array}$ & $\begin{array}{l}\text { ARTES. plur. Se toma tambien por las ciencias } \\
\text { Lógica, Física, y Metafísica, y así se dice: curso } \\
\text { de artes, lector de artes \&c. Artes. Lop. Comed. La } \\
\text { Escolástica zelosa, jorn. } 3 \text {. Estos votos habran sido / } \\
\text { De alguna cátedra de artes. }\end{array}$ \\
\hline
\end{tabular}

Como se ha señalado, se afianza el uso de la abreviatura v. g., que en el primer Autoridades solo figuraba en el sexto volumen y que ahora puede sustituir a cualquiera de las fórmulas empleadas anteriormente.

\begin{tabular}{|l|l|}
\hline \multicolumn{1}{|c|}{ Diccionario de autoridades } & \multicolumn{1}{|c|}{ Diccionario de autoridades 1770} \\
\hline $\begin{array}{l}\text { BoDEga. Se toma por la cosecha, ò la abundáncia } \\
\text { de algun lugar que coge mucho vino: y assi se dice, } \\
\text { La bodéga de Valdemóro, la de Sahagún, \&c... }\end{array}$ & $\begin{array}{l}\text { BODEGA. La cosecha en general ó mucha } \\
\text { abundancia de vino de algun lugar. v. g. La bodega } \\
\text { de Valdemoro, de Sahagun \&c... }\end{array}$ \\
\hline
\end{tabular}

Como se comprueba en los ejemplos anteriores, además, el uso de la cursiva para marcar el lema dentro del ejemplo ya no es esporádico y va sustituyendo a la mayúscula inicial.

Dejando ya a un lado la manera de introducir las notas y ejemplos en el discurso lexicográfico, conviene destacar que, como sucedía en la primera edición, en la segunda ambos elementos conviven con las citas de autoridades. Así, en dos nuevas entradas de 1770, anclage y babor $^{10}$, el ejemplo real va precedido, en el primer caso, de uno inventado ${ }^{11} \mathrm{y}$, en el segundo, de una nota de uso.

8 El hito más importante en este sentido no ocurre en las ediciones de la primera mitad del XIX, sino en la duodécima edición (DRAE 1884), cuando se convierten en fórmulas abreviadas que aparecen tras la definición, como posmarcas. La transformación puede observarse en tiniebla.

\begin{tabular}{|l|l|}
\hline \multicolumn{1}{|c|}{ Diccionario de autoridades } & \multicolumn{1}{c|}{ DRAE 1884 } \\
\hline $\begin{array}{l}\text { TINIEBLA. s. f. Carencia, falta, y privación total de luz. Usase } \\
\text { comunmente en plural... }\end{array}$ & $\begin{array}{l}\text { tiniebla. (Del lat. tenebrae.) f. Carencia, falta y privación de } \\
\text { luz. Ú. m. en pl.... }\end{array}$ \\
\hline
\end{tabular}

9 También se mantienen hasta 1884, cuando se pierden las fórmulas introductorias y el ejemplo se resalta en cursiva (dentro de él, la palabra ejemplificada aparece en versalita). Por ejemplo, la acepción plural de arte se halla formulada en la duodécima edición como "Lógica, física y metafísica. Curso de ARTES" (DRAE 1884).

10 Consideramos babor como nueva entrada, aunque en la primera edición de Autoridades se recogía babord como voz francesa, con una breve definición y sin ejemplo alguno.

11 No obstante, de acuerdo con los datos que ofrece Pascual Fernández (2013: 172), son más frecuentes los casos en los que no concurren ejemplo real e inventado. 
ANCLAGE. s. m. El acto de anclar las naves, y tambien el sitio y lugar para ello. Y así se dice, tal puerto tiene buen ó mal anclage. Anchorae jactus, vel locus his jaciendis opportunus. Silvestr. Prosep. cant. 7. oct. 11. Que salva hicimos sin tomar anclage.

BABOR. s. m. El lado ó costado izquierdo del navio, del que estando á popa mira á proa. Úsase con algunas partículas, como á babor, de babor, por babor. Sinistrum navigii latus. ORDEN. DE MARIN. part. I. trat. 3. tít. 5. art. 3. En los demás camarotes alojarán los oficiales de guerra y ministerio según su carácter, eligiendo cada uno en su lugar el que quisiere á babor ó estribor.

Asimismo, como se ilustra en las entradas de abarrisco y absolvederas, pueden introducirse notas de uso nuevas manteniéndose la autoridad de 1726.

\begin{tabular}{|c|c|}
\hline Diccionario de autoridades & Diccionario de autoridades 1770 \\
\hline $\begin{array}{l}\text { ABARRISCO. adv. Indistinta y } \\
\text { desordenadamente, sin modo ni consideración } \\
\text { algúna, y lo mismo que sin repáro y } \\
\text { atropelladamente. [...] Quev. Cuent. Voto à tal y } \\
\text { à qual, que todo lo havía de llevar abarrisco. Qué } \\
\text { es abarrisco en mis barbas? dixo el Padre. Ming. } \\
\text { Revulg. Copl. 28. Cata que vendrá el pedrisco, / } \\
\text { que lleva todo abarrisco. }\end{array}$ & $\begin{array}{l}\text { ABARRISCO. adv. antiq. Sin distincion, } \\
\text { consideracion ni reparo. Usábase comunmente } \\
\text { con el verbo llevar. Hoy tiene algun uso entre } \\
\text { la gente rústica. Indiscriminatim, promiscuè. } \\
\text { QuEV. Cuent. Voto à tal y à qual que todo lo } \\
\text { había de llevar abarrisco. Ming. REvUlg. copl. } \\
\text { 28. Cata que vendrá el pedrisco, / que lleva todo } \\
\text { abarrisco. }\end{array}$ \\
\hline $\begin{array}{l}\text { ABSOLVEDERAS. s. f. usado siempre en plurál. } \\
\text { Voz jocosa y familiár, con que se suele notar en } \\
\text { algunos Confessóres la facilidád en absolver. } \\
\text { Lat. Indiscreta à noxis absolvendi facilitas. } \\
\text { BARB. Cab. punt. fol. } 97 \text {. Hombre franco, y de } \\
\text { admirables absolvedéras. }\end{array}$ & $\begin{array}{l}\text { ABSOLVEDERAS. s. f. plur. fam. con que suele } \\
\text { expresarse la facilidad en absolver de algunos } \\
\text { Confesores. Úsase las mas veces con algunos } \\
\text { adjetivos como buenas, grandes ó bravas } \\
\text { absolvederas. Indiscreta á noxis absolvendi } \\
\text { facilitas. BARB. Cab. punt. fol. } 97 \text {. Hombre } \\
\text { franco, y de admirables absolvederas. }\end{array}$ \\
\hline
\end{tabular}

No obstante, se documentan numerosos casos de supresión o simplificación de notas y ejemplos con la mencionada tendencia al acortamiento, como en avenir 'concordar' o aventajado 'primoroso"12, y paralelamente se incrementan las notas de carácter morfosintáctico (el uso adjetivo de aventajado y las notas de uso recíproco en los verbos como la que se encuentra en avenir).

12 Estas dos entradas son claros exponentes de reducción. Además de la supresión de los ejemplos inventados, en avenir se eliminan dos de las tres citas de 1726; en aventajado, con un solo ejemplo real, el texto citado queda reducido a tres palabras. 


\begin{tabular}{|c|c|}
\hline Diccionario de autoridades & Diccionario de autoridades 1770 \\
\hline $\begin{array}{l}\text { AVENIR. v. a. Concordar, concertar, ajustar } \\
\text { y conciliar à los que están discordes, haciendo } \\
\text { que se unan y conformen. Este verbo es mas } \\
\text { usado en passíva, y assi comunmente se dice } \\
\text { las partes se avinieron, se compusieron y } \\
\text { concertaron. Viene del Latino Venire, y tiene } \\
\text { las mismas anomalías que el simple venir. Lat. } \\
\text { Dissidentes conciliare, conjungere, pacificare. } \\
\text { PARTID. 5. tit. 14. 1. 34. Por miedo que han los } \\
\text { demandadores de perder sus demandas avienense } \\
\text { con los demandádos... }\end{array}$ & $\begin{array}{l}\text { AVENIR. v. a. Concordar, ajustar las partes } \\
\text { discordes. Úsase mas comunmente como } \\
\text { recíproco. Conciliare, componere, lites \& } \\
\text { dissidia sedare. Part. 5. tít. 14. 1. 34. Por } \\
\text { miedo que han los demandadores de perder sus } \\
\text { demandas aviénense con los demandados. }\end{array}$ \\
\hline $\begin{array}{l}\text { AVENTAJADO. Se llama tambien lo perfecto, } \\
\text { primoroso y bien executado: y assi se dice de una } \\
\text { alhája ò artificio hecho con todo primór, que } \\
\text { es mui aventajádo. Lat. Praestans. Excellens. } \\
\text { Acost. Hist. Ind. lib. 4. cap. 29. Huvo muchos } \\
\text { grandes hombres de curar con simples, y hacían } \\
\text { curas aventajádas. }\end{array}$ & $\begin{array}{l}\text { AVENTAJADO. Usado como adjetivo vale } \\
\text { primoroso, excelente. Praestans, excellens. } \\
\text { Acost. Hist. Ind. lib. 4. cap. 29. Hacian curas } \\
\text { aventajadas. }\end{array}$ \\
\hline
\end{tabular}

La adición y supresión de notas y ejemplos se da en todas las ediciones, pero tampoco es raro que se mantengan los mismos ejemplos desde Autoridades hasta los diccionarios de finales del siglo xx y aún del xxI, como ocurre en no andemos en cháncharras máncharras (s. v. cháncharras máncharras); despedir al soldado, las tropas (s. v. despedir); mudar casa, vestido (s. v. mudar); amor trompero (s. v. trompero); etc.

En la segunda edición de Autoridades, además, con la intensa reescritura de las definiciones se van modificando las referencias al uso. Se producen frecuentes trasvases de información entre el lema y las notas y ejemplos, lo que da lugar a la simplificación de algunos lemas complejos, como se puede apreciar en la entrada acuerdo.

\begin{tabular}{|l|l|}
\hline \multicolumn{1}{|c|}{ Diccionario de autoridades } & \multicolumn{1}{|c|}{ Diccionario de autoridades 1770 } \\
\hline Quedar, ò estar de acuerdo. Es lo mismo que & DE ACUERdo. mod. adv. De conformidad, \\
conformarse, y ser de un mismo dictámen en lo & unánimemente. Úsase por lo comun con los \\
que se ha de hacer. Lat. Inter nos vel eos convenit. & verbos estar, quedar, y ponerse. Uno consensu. \\
Convenimus. Nobis optimè convenit. Cerv. Quix. & CERv. Quix. tom. 2. cap. 5. En efecto quedamos \\
tom. 2. cap. 5. En efecto quedamos de acuerdo, & $\begin{array}{l}\text { de acuerdo, dixo Sancho, de que ha de ser } \\
\text { dixo Sancho, de que ha de ser Condesa nuestra } \\
\text { Condesa nuestra hija. } \\
\text { hija? Argens. Maluc. lib. 3. fol. 133. Todos }\end{array}$ \\
estuvieron de acuerdo. & \\
\hline
\end{tabular}

Como muestra este ejemplo, la primitiva locución verbal quedar o estar de acuerdo pasa a considerarse en 1770 una locución adverbial, de acuerdo, que es el nuevo lema, mientras que los principales verbos con los que se combina — quedar, estar y el recién incorporado ponerse - se mencionan en una nota de uso. Asimismo, se registra la actuación contraria: hay notas o ejemplos que dan lugar a nuevos lemas, normalmente complejos. 
Así, en la entrada ave maría se suprime el ejemplo de 1726 para introducir la locución adverbial al ave maría en la nomenclatura.

\begin{tabular}{|l|c|}
\hline \multicolumn{1}{|c|}{ Diccionario de autoridades } & Diccionario de autoridades 1770 \\
\hline Ave MARIA. Se llama la hora última del dia en que & AL AVE MARía. mod. adv. que vale lo mismo \\
empieza la noche, por la santa y loable costumbre de & que al anochecer. Dícese así por la loable \\
rezar al toque de las campanas la salutación angélica en & costumbre que hay de tocar las campanas \\
memória del gloriosissimo mystério de la Encarnación: & y rezar la salutacion angélica en memoria \\
y assi se dice Al Ave María llegamos à casa, al Ave & de la Encarnacion. Adventante nocte. \\
María se alzó de obra: esto es al anochecer... & \\
\hline
\end{tabular}

Estos trasvases de información resultan sumamente interesantes, pues evidencian un problema sintáctico con implicaciones lexicográficas: los límites, no siempre claros, entre las unidades léxicas pluriverbales — que deben formar parte del diccionario como lemas complejos - y las combinaciones frecuentes - de las que puede quedar constancia como muestra de lengua prototípica en una nota o un ejemplo, pero que no deben formar parte de la nomenclatura del diccionario-. Avenido ilustra cómo la información sobre el uso consignada en notas y ejemplos pasa a la nomenclatura con lema complejo, por la evolución que se muestra en el tratamiento normativo de la expresión bien/mal avenido.

\begin{tabular}{|l|l|}
\hline \multicolumn{1}{|c|}{ Diccionario de autoridades } & \multicolumn{1}{|c|}{ Diccionario de autoridades 1770} \\
\hline AVENIDO, DA. part. pas. del verbo Avenir. & AVENIDO, DA. part. pas. del verbo avenir. \\
Ajustado y convenído, y tambien unído, & BIEN ó MAL AVENIDOs. Se dice de los que están \\
conforme y concorde. En esta última acepción & concordes ó discordes en los ánimos. Corde \& \\
se usa casi siempre con los adverbios Bien, ò & animo concordes, vel discordes. FEIX. Teatr. tom. \\
mal, diciendo bien avenído, mal avenído: y & 6. fol. 155. Entre los confinantes suele reynar \\
atendido el significado recto de esta palabra el & cierta especie de emulacion que los hace mal \\
adverbio Bien realmente está demás, y en rigór & avenidos. \\
es pleonasmo, y el adverbio mal es contrário à la & \\
significación; pero el uso común de la lengua ha & \\
calificado este abúso... & \\
\hline
\end{tabular}

En el primer Autoridades, tras la nota de uso se censura el "pleonasmo" bien avenido y la "contradicción" mal avenido. En 1770, la aceptación de las construcciones implica un cambio en la definición y la adición del lema complejo bien ó mal avenidos; además, se incorpora una cita literaria que corrobora, como autoridad, el uso antes censurado. Nota de uso y ejemplo se sustituyen, pues, por una nueva entrada cuyo contenido supone, por otra parte, una actualización de la información que proporciona el diccionario. Las notas y ejemplos de uso pueden ser, por lo tanto, una fuente para la introducción de los sublemas que se añaden a las entradas.

Una tendencia generalizada en el paso de la primera edición a la segunda de Autoridades, que se prolonga en el diccionario usual, es la sustitución de las notas de uso por ejemplos. Puede observarse una muestra de este cambio en una de las acepciones de averiguar, en la que la información gramatical que se consignaba mediante una nota se incorporará indirectamente mediante la adición de dos ejemplos. Además, tampoco en este caso la introducción del ejemplo implica la supresión de las citas. 


\begin{tabular}{|c|c|}
\hline Diccionario de autoridades & Diccionario de autoridades 1770 \\
\hline $\begin{array}{l}\text { AVERIGUARSE. v. r. Componerse, ajustarse con uno, } \\
\text { reducirle y sujetarle à la razón. Usase freqüentemente } \\
\text { en estos significados, y de ordinário se le junta la } \\
\text { partícula No. Lat. Adigere seu cogere aliquem ad } \\
\text { officium. QUEV. Fort. No se podían averiguar con la } \\
\text { carnicería que le havían devorádo. CERV. Quix. tom. } \\
\text { I. cap. } 7 \text {. El Cura algunas veces le contradecía, y otras } \\
\text { concedía: porque sino guardaba este artificio no havía } \\
\text { poder averiguarse con él. }\end{array}$ & $\begin{array}{l}\text { AVERIGUARSE CON ALGUNO. Fras. fam. Avenirse } \\
\text { con alguno, sujetarle ó reducirle á la razon; y } \\
\text { así se dice: no hay quien se averigüe con él: } \\
\text { no me puedo averiguar con este muchacho } \\
\text { \&c. Aliquem ad justum redigere, rationi } \\
\text { subjicere. CERV. Quix. tom. I. cap. } 7 \text {. El cura } \\
\text { algunas veces le contradecia, y otras concedia, } \\
\text { porque si no guardaba este artificio, no habia } \\
\text { poder averiguarse con él. }\end{array}$ \\
\hline
\end{tabular}

El Diccionario de autoridades de 1770, pues, sigue la senda iniciada por su predecesor en cuanto a la atención al uso. Aunque no falta la supresión de notas y ejemplos, este tipo de información sigue formando parte de las entradas nuevas, al tiempo que se añade en otras ya existentes. Se atestigua, además, la intensa labor de revisión y reescritura de los artículos, que propicia las modificaciones de los lemas partiendo de información que se ofrecía en las notas o se percibía en los ejemplos, y viceversa.

\section{DEL DICCIONARIO DE AUTORIDADES AL DICCIONARIO USUAL (1780-1803)}

Un cambio fundamental se produce en la edición del diccionario en 1780 con la publicación de un compendio con el título Diccionario de la lengua castellana, reducido a un tomo para su más fácil uso con el fin de satisfacer las demandas del público (Seco 1991 [2003]). Se consideran, en primer lugar, las cuatro primeras ediciones del diccionario usual.

\subsection{EI DRAE 1780}

El "compendio" publicado en 1780 surge de la reducción que se lleva a cabo básicamente a costa de la supresión de las citaciones textuales, junto a ciertos cambios tipográficos y a la ampliación del sistema de abreviaturas ya iniciado en 1770, a lo que habría que añadir la supresión de las etimologías aducida en el prólogo del diccionario (Seco 1991 [2003]: 241, Ruhstaller 2004: 250-252, Rivera 2009). Conviene recordar que el proceso del que surge es complejo y, en consecuencia, en este diccionario se pueden distinguir, siguiendo a Seco (1991 [2003]: 244), "tres niveles cronológicos distintos": “1. ${ }^{\circ}$, el de $1770 ; 2 .^{\circ}$ el de 1780, formado por el Suplemento, redactado en este año, y por el manuscrito de la segunda edición del tomo II, que en esa fecha estaba terminado y que muy bien hubiera podido publicarse entonces; y $3 .^{\circ}$, el de 1732-1739, procedente de la primera edición, sin más cambios que los impuestos por la nueva ortografía".

En este punto los ejemplos textuales y los ejemplos inventados del Diccionario de autoridades inician un camino diferente, pues mientras los primeros desaparecen del diccionario, los segundos son "salvados de la condena" (Seco 1991 [2003]: 249), de manera que en algunos casos, como ya se ha apuntado, es posible encontrar ejemplos de las últimas ediciones del diccionario académico que remontan su aparición al propio Diccionario de autoridades o a una de las primeras ediciones del diccionario usual. 
Aunque la supresión de las citas no implica que la atención al uso desaparezca del diccionario, la reducción se verifica también en algunos aspectos relativos a las notas y ejemplos inventados. Así, en el cambio de Autoridades a los diccionarios en un solo volumen se pierde algo muy característico del discurso lexicográfico del primer diccionario: las explicaciones y glosas sobre el verdadero significado de los ejemplos. Se trata, como viene siendo habitual en la evolución del diccionario, de un cambio no sistemático, sino paulatino, que depende, en una primera fase, del curso seguido en la revisión del Diccionario de autoridades: cháncharras máncharras pierde su explicación en la primera edición del diccionario usual (1780), mientras que decible lo hará en la tercera (1791), por mencionar solo dos ejemplos.

\begin{tabular}{|c|c|}
\hline Diccionario de autoridades & $D R A E$ \\
\hline $\begin{array}{l}\text { CHANCHARRAS MANCHARRAS. Modo de } \\
\text { hablar vulgar y baxo, que usa la gente común, y } \\
\text { vale lo mismo que cuentos, engaños, ù dispútas: } \\
\text { y assi se dice, No andémos en cháncharras } \\
\text { máncharras, como dando à entender que no } \\
\text { lo sufrirá. Lat. Importunae oblocutiones. Aliena } \\
\text { dicta. QUEV. Cuent. La pupiléra que tenía pulgas, } \\
\text { soltó la taravilla, y dixo claramente, que ella era } \\
\text { mujer de sangre en el ojo, y que con ella no havía } \\
\text { cháncharras máncharras. }\end{array}$ & $\begin{array}{l}\text { CHANCHARRAS MANCHARRAS. loc. } \\
\text { bax. Rodeos, ó pretextos para dexar de hacer } \\
\text { alguna cosa. Usase mas comunmente con } \\
\text { el verbo andar; y así se dice: no andemos } \\
\text { en CHANCHARRAS MANCHARRAS. Praetextus, } \\
\text { obtentus. (DRAE 1780). }\end{array}$ \\
\hline $\begin{array}{l}\text { DECIBLE. adj. de una term. Lo que se puede } \\
\text { decir. Comunmente se junta con la partícula } \\
\text { No: como No es decible esto, y equivále à No } \\
\text { es creíble, no es ponderáble. Lat. Infandum est. } \\
\text { Ov. Hist. Chil. lib. 1. cap. } 1 \text {. No es decíble las } \\
\text { alegrías que hacen, y contento que muestran, por } \\
\text { parecerles que han vuelto a su Patria. }\end{array}$ & $\begin{array}{l}\text { DECIBLE. adj. Lo que se puede decir. } \\
\text { Comunmente se junta con la partícula no: } \\
\text { como es DECIBLE esto, y equivale, no es creible, } \\
\text { no es ponderable. Infandum est (DRAE 1780). } \\
\text { DECIBLE. adj. Lo que se puede decir. Úsase } \\
\text { mas comunmente con la negacion, como no es } \\
\text { DECIBLE, ni es DECIBLE. Quod dici potest (DRAE } \\
\text { 1791). }\end{array}$ \\
\hline
\end{tabular}

En ocasiones, la supresión de la autoridad va acompañada de la supresión de la información de uso, con una considerable reducción del artículo lexicográfico, como se aprecia en una de las acepciones de crédito.

\begin{tabular}{|l|ll|}
\hline \multicolumn{1}{|c|}{ Diccionario de autoridades } & \multicolumn{1}{|c|}{ DRAE 1780 } \\
\hline CREDITO. Por extensión significa seguridád, & CRÉDITO. Apoyo, abono, comprobacion. \\
apóyo, abono, firmeza y comprobacion de algúna & Comprobatio, comendatio. & \\
cosa: y assí comunmente se dice, En crédito de & & \\
esta verdad, noticia, sucesso, y assí de otras & & \\
varias cosas: esto es, En abóno, seguridád y \\
certéza de ellas, \&c. Lat. Fides, ei. Auctoritas, \\
tis. Mond. Dissert. 2. cap. 1. Palabras que dexan \\
ociosa la ponderacion en crédito del buen juicio \\
de quien las pronunció.
\end{tabular}


Pero, en otros casos, la única actuación que registra el artículo desde Autoridades al diccionario usual se halla en la supresión de la cita, manteniéndose de forma literal notas y ejemplos.

\begin{tabular}{|c|c|}
\hline Diccionario de autoridades & DRAE 1780 \\
\hline $\begin{array}{l}\text { DILIGENCIA. En el trato familiár vale negócio, dependéncia, solicitúd } \\
\text { particulár: y assí se dice comunmente, Tengo que ir o que hacer una } \\
\text { diligéncia. Lat. Negotium, ii. SANT. TER. Cart. tom. } 2 \text {. Cart. } 43 \text {. num. } 8 \text {. } \\
\text { Encomiendelo V. R. a Dios, que toda la diligéncia possible se hará. CERV. } \\
\text { Quix. tom. 2. cap. } 65 \text {. Y no le diré nada, por vér si salgo verdadéro en } \\
\text { sospechar que no ha de tener efecto la diligéncia hecha por el señor Carrasco. }\end{array}$ & $\begin{array}{l}\text { DILIGENCIA. fam. Negocio, } \\
\text { dependencia, solicitud } \\
\text { particular; y así se dice } \\
\text { comunmente: tengo } \\
\text { que ir, ó que hacer una } \\
\text { DILIGENCIA. Negotium. }\end{array}$ \\
\hline
\end{tabular}

Los ejemplos se modifican en ocasiones para adaptarse a la reescritura de los artículos. Así, en crecer, la separación de acepciones llevada a cabo en 1780 trae aparejada la transformación de los ejemplos, que aclaran las nuevas definiciones y ofrecen información combinatoria - en concreto, sobre los sustantivos que pueden ejercer la función de sujeto cuando el verbo adopta el significado que se menciona-.

\begin{tabular}{|c|c|}
\hline Diccionario de autoridades & DRAE 1780 \\
\hline $\begin{array}{l}\text { CRECER. v. n. Aumentarse, venir à ser } \\
\text { mayór, agrandarse algúna cosa, yá sea } \\
\text { sensible, insensible ò metaphórica: como el } \\
\text { hombre crece, el arbol crece, la mar crece, } \\
\text { la virtud, la malicia y los precios crecen. } \\
\text { Viene del Latino Crescere, que significa esto } \\
\text { mismo. Este verbo tiene la anomalía de los } \\
\text { acabados en ecer: como Yo crezco, crezca } \\
\text { aquel. PART. 1. tit. } 4 \text {. 1. } 61 \text {. E otrosi debe } \\
\text { llevar Cruz è agua bendita, è una campanilla } \\
\text { tañiendo, porque entiendan los homes que se } \\
\text { deben humillar à... }\end{array}$ & $\begin{array}{l}\text { CRECER. v. n. Tomar aumento insensiblemente los } \\
\text { cuerpos naturales. Crescere, augeri. } \\
\text { CRECER. Tomar aumento alguna cosa por añadírsele } \\
\text { exteriormente nueva materia, como quando decimos } \\
\text { que CRECEN los rios y los arroyos. Accrescere, } \\
\text { augeri. } \\
\text { CRECER. Tomar aumento algunas cosas respecto de } \\
\text { nosotros, y en este sentido se dice: que CRECE la } \\
\text { luna, el mar, los dias, \&c. Crescere. }\end{array}$ \\
\hline
\end{tabular}

En mudar, sin embargo, la modificación en el ejemplo obedece a razones sintácticas: el cambio en la construcción del verbo, presentado como transitivo en Autoridades y como intransitivo en el primer usual.

\begin{tabular}{|l|l|}
\hline Diccionario de autoridades & DRAE 1780 \\
\hline MUDAR. En lo moral vale variar: y assí se dice & MUDAR. En lo moral vale variar; y asi se dice: \\
Mudar dictamen, parecer, \&c. Lat. Variare. & MUDAR de dictámen, parecer, \&c. Variare. \\
Lop. Circ. f. 110. Habiendo oído Felisardo... & \\
algunos años la facultad de Cánones, mudó & \\
intento por algunos respétos: y viniendo a la & \\
Corte de Philipo Tercero, llamado el Bueno, & \\
aplicóse a servir en la casa de un Grande de los & \\
más conocidos destos Réinos. & \\
\hline
\end{tabular}


Como en el paso de la primera a la segunda edición de Autoridades, se verifican en la transformación de Autoridades al diccionario de 1780 y las ediciones posteriores trasvases entre la información que proporcionan la microestructura y la macroestructura, con ejemplos que se constituyen en nuevos lemas complejos, como en creciente de la luna. En el caso del lema creciente $^{13}$, también la agrupación sintagmática registrada en un ejemplo real de Ambrosio de Morales del Diccionario de autoridades da lugar a un nuevo lema complejo, creciente de la mar, en el diccionario de 1780.

\begin{tabular}{|c|c|}
\hline Diccionario de autoridades & DRAE 1780 \\
\hline $\begin{array}{l}\text { CRECIENTE. part. act. del verbo Crecer. Lo } \\
\text { que crece y se vá aumentando. Latín. Crescens. } \\
\text { BAREN, Guerr. de Fland. pl. 350. Viniesse a } \\
\text { aumentarle más la reputación y gloria, a que su } \\
\text { creciente fama militar le havía hasta entonces } \\
\text { ensalzado. REBOLL. Ocios, fol. 207. Mar de } \\
\text { tafetan azúl, / que es puntas de oro su margen, / } \\
\text { en aguas crecientes dá / con todo baxel al traste. } \\
\text { CRECIENTE. s. f. El aumento que los rios y } \\
\text { arroyos toman quando ha llovido mucho: y } \\
\text { tambien se llama assi el que por el fluxo y refluxo } \\
\text { toma la mar. Lat. Fluvii exundatio. Inundatio. } \\
\text { Fr. L. DE GRAN. Symb. part. 1. cap. 9. Porque } \\
\text { de las aguas vemos que proceden las avenidas y } \\
\text { crecientes de los rios, que hacen notable daño en } \\
\text { las tierras vecinas. AmBR. Mor. tom. 1. fol. } 156 . \\
\text { Mas quando quiso desembarcar, no pudo: que la } \\
\text { creciente de la mar se lo estorbó. RoDRIG. Exerc. } \\
\text { tom. } 1 \text {. trat. 1. cap. 9. De unas pequeñas gotas } \\
\text { de agua multiplicadas, se vienen à hacer unas } \\
\text { crecientes y avenidas tan grandes, que echan } \\
\text { por tierra los grandes muros, y los edificios y } \\
\text { castillos fuertes. } \\
\text { CRECIENTE. Metaphoricamente se dice de otras } \\
\text { cosas que no son corrientes, y vale tanto como } \\
\text { Aumento: como La creciente de la Luna, de } \\
\text { la fama, de las riquezas, \&c. Lat. Augmentum. } \\
\text { Incrementum. PARR. Luz de Verd. Cath. Plat. } 18 \text {. } \\
\text { del Sacramento de la Penitencia. Vino el Sastre } \\
\text { quando estaba la Luna en creciente, tomóle las } \\
\text { medidas, y mientras lo cosía, quando volvió à } \\
\text { probarlo le venía tan estrecho, tan angosto, que } \\
\text { ni entrar pudo. }\end{array}$ & $\begin{array}{l}\text { CRECIENTE. p. a. de CRECER. Lo que crece y se } \\
\text { aumenta. Crescens. } \\
\text { CRECIENTE. s. m. En el blason se llama así una } \\
\text { media luna con las puntas hácia arriba. Crescens. } \\
\text { CRECIENTE. s. f. El aumento de aguas que toman } \\
\text { los ríos, ó arroyos por las grandes lluvias, ó por } \\
\text { derretirse la nieve. Eluvies. } \\
\text { CRECIENTE. p. Mur. y otr. part. Levadura. } \\
\text { Fermentum. } \\
\text { CRECIENTE DE LA LuNA. El tiempo que pasa desde } \\
\text { el novilunio al plenilunio, en el cual siempre va } \\
\text { apareciendo mayor. Llámase quarto creciente } \\
\text { la primera quadratura, esto es, quando llega á } \\
\text { verse la mitad de la luna entre el novilunio y el } \\
\text { plenilunio. Lunae crescdentia, crescentis lunae } \\
\text { tempus, spatium. } \\
\text { CRECIENTE DE LA MAR. La subida que hace el agua } \\
\text { del mar dos veces al dia, que tambien se llama } \\
\text { fluxo. AEstus, maris fluxus. }\end{array}$ \\
\hline
\end{tabular}

13 En el Diccionario de autoridades existen dos entradas para creciente, la primera de ellas se encuentra inmediatamente después de crecer y antes de crecido. La segunda figura en el lugar alfabético correspondiente. Las dos entradas se funden en una sola en el DRAE 1780. 
Además, junto a la consolidación del uso de los dos puntos tras la fórmula introductoria de ejemplos y así se dice (cfr. cháncharras máncharras, crecer y mudar), en el primer diccionario usual se da un importante cambio tipográfico que se mantiene hasta la vigesimoprimera edición (1992): el uso de la versalita para resaltar en el ejemplo el lema o la expresión que se pretende ilustrar, como se comprueba en la entrada aceros (cfr. cháncharras máncharras, crecer, decible, diligencia y mudar).

\begin{tabular}{|c|c|}
\hline Diccionario de autoridades 1770 & DRAE 1780 \\
\hline $\begin{array}{l}\text { ACEROS. fam. Las ganas de comer. Úsase } \\
\text { comunmente con los adjetivos buenos, } \\
\text { valientes, \&c. y así se dice, sentóse á comer con } \\
\text { buenos aceros. Esuries, edendi cupiditas. }\end{array}$ & $\begin{array}{l}\text { ACEROS. fam. Las ganas de comer. Úsase } \\
\text { comunmente con los adjetivos buenos, } \\
\text { valientes, \&c. y así se dice, sentóse á comer con } \\
\text { BUENOS ACEROS. Esuries, edendi cupiditas. }\end{array}$ \\
\hline
\end{tabular}

En el $D R A E$ 1780, por tanto, la supresión de las citas no significa que la atención al uso desaparezca del diccionario. A diferencia de los ejemplos reales, los ejemplos inventados y las notas de uso se mantienen, aunque no exentos de cambios (cfr. Pascual Fernández 2012).

\subsection{El $D R A E 1783$ y 1791}

En 1783, solo tres años después de la publicación de la primera edición del diccionario en un solo tomo, aparece la segunda. El escaso margen de tiempo que hay entre ambas publicaciones justifica las escasas diferencias entre ellas, algo que se puede extender también a la tercera edición. Ya observó Alvar Ezquerra (2005: 8) que "el número de las entradas de estas dos ediciones es similar a las que hay en la de 1780, pues la rapidez con las [sic] que se suceden las ediciones no permiten muchos cambios". El DRAE 1783 contiene un suplemento para las tres primeras letras del abecedario, mientras que la edición de 1791 anuncia en la portada nuevos artículos para las tres letras siguientes $(D, E$ y $F$, cfr. Álvarez de Miranda 2000: 48-49) $)^{14}$.

No es raro, pues, que no constatemos en nuestro estudio cambios en lo que a las notas y ejemplos se refiere en el DRAE 1783, aunque tres adiciones de su suplemento, alamparse, aprender y capitolino, incorporan ejemplos de uso que pasarán en 1791 al cuerpo del diccionario.

ALAMPARSE. v. r. Tener ansia grande por alguna cosa singularmente de comer, ó beber; y así se dice: me alampo por comer, me estoy alampando de sed. Anxium ese, avidè cupere.

APRENDER. v. a. Lo mismo que decorar, ó tomar de memoria; y así decimos: APRENDER la lección, APRENDER el sermón, \&c.

CAPITOLINO. adj. Lo que pertenece al Capitolio; y así se dice: Júpiter capitolino, monte capitolino. Capitolinus.

14 La portada dice literalmente así: "Tercera edicion, en la qual se han colocado en los lugares correspondientes todas las voces de los suplementos, que se pusieron al fin de las ediciones de los años de 1780 y 1783 , y se han intercalado en las letras D. E. y F. nuevos artículos, de los quales se dará un suplemento separado". Sin embargo, a diferencia de la segunda, esta edición no incorpora suplemento. 
La mayor parte de las entradas que ofrece el suplemento de 1783 son remisiones encabezadas por lo mismo que. El peso de la información sinonímica se manifiesta también en la presencia de notas de uso introducidas para mencionar voces equivalentes, a veces dos, como en acalía y círculo.

ACALÍA. s. f. Yerba. Lo mismo que ALTEA, que vulgarmente se llama malvavisco.

CÍRCULO. s. m. Ret. Especie de conduplicación, y es quando una cláusula acaba con la voz que empezó. Dícese tambien orbe, PERíodo. Circulus, epanadiplosis.

En las calas realizadas en el DRAE 1791, puede observarse que la particular atención de esta edición a la información no actual, que se percibe en un buen número de incorporaciones con la marca ant. (dadivar, dalgo, dalí, dalind, dalgund, etc.), se extiende también a la redacción de notas en pasado, como la añadida en la quinta acepción de don.

DON. [...] 5. Sin estar acompañado de otro nombre, y por sí solo significaba SEÑoR; y con algun adjetivo, ó epíteto, era lo mismo que sẼ̃or. Dominus.

La notable reescritura que puede observarse en esta parte del diccionario denota tendencias contrarias, pues no es raro constatar la inclusión de observaciones relacionadas con el uso, como ocurre en danzante, doctrina, donde y duendo.

\begin{tabular}{|l|l|}
\hline \multicolumn{1}{|c|}{ DRAE 1783 } & \multicolumn{1}{|c|}{ DRAE 1791 } \\
\hline $\begin{array}{l}\text { DANZANTE. Apodo con que se moteja á } \\
\text { algun sugeto de juicio, entremetido y } \\
\text { atrevido; y así se dice: fulano es bravo } \\
\text { DANZANTE, lindo DANZANTE... }\end{array}$ & $\begin{array}{l}\text { DANZANTE, TA. [...] 2. met. El que no se descuida en } \\
\text { su negocio, y obra con agilidad, maña y actividad: y así se } \\
\text { dice es bravo DANZANTE, es un buen DANZANTE. Tambien } \\
\text { se aplica al que es ligero de juicio, muy entrante y saliente, } \\
\text { y de este se dice por apodo: es un DANZANTE... }\end{array}$ \\
\hline $\begin{array}{l}\text { DOCTRINA. El concurso de gente, que con } \\
\text { los predicadores sale en procesion por } \\
\text { las calles hasta el parage en que se ha de } \\
\text { hacer la plática. }\end{array}$ & $\begin{array}{l}\text { DOCTRINA [...] 5. El concurso de gente que con los } \\
\text { Predicadores sale en procesion por las calles hasta el } \\
\text { parage en que se ha de hacer la plática; y así se dice: por } \\
\text { tal parte, ó calle pasa la poctRINA, \&c. }\end{array}$ \\
\hline $\begin{array}{l}\text { DONDE. adv. l. Lo mismo que ADONDE. } \\
\text { DONDE. adv. l. Lo mismo que ADONDE. Usase con verbos } \\
\text { de quietud y de movimiento. 2. Se junta algunas veces } \\
\text { con las personas en lugar de EN QUE, ó EN QUIEN. }\end{array}$ \\
\hline $\begin{array}{l}\text { DUENDO, DA. adj. Lo mismo que } \\
\text { MANDO Y CASERO. }\end{array}$ & $\begin{array}{l}\text { DUENDO, DA. Lo mismo que MANDO, ó DOMÉSTICO. } \\
\text { Llámanse así particularmente las palomas caseras. }\end{array}$ \\
\hline
\end{tabular}

Sin embargo, en otros casos se verifica cierta simplificación de los artículos mediante la reducción de las notas y ejemplos de uso, como se constata en dudable, reducción que se une a la de la definición, o como ocurre en la acepción de dar que se menciona a continuación: 


\begin{tabular}{|l|l|}
\hline \multicolumn{1}{|c|}{ DRAE 1783} & \multicolumn{1}{|c|}{ DRAE 1791 } \\
\hline $\begin{array}{l}\text { DUDABLE. adj. Lo que se puede dudar, ó tiene } \\
\text { duda. Las mas veces se usa con negación, para } \\
\text { afirmar alguna cosa. Dubitabilis. }\end{array}$ & $\begin{array}{l}\text { DUDABLE. adj. Lo que se puede dudar. Dubius, } \\
\text { incertus. }\end{array}$ \\
\hline $\begin{array}{l}\text { DAR. Se usa tambien por ordenar, aplicar y y } \\
\text { acudir, como DAR el remedio al enfermo, DAR el } \\
\text { consejo, el consuelo al dudoso, ó desconsolado. } \\
\text { Remedium adhibere. }\end{array}$ & $\begin{array}{l}\text { DAR. [...] 4. Ordenar, aplicar, como el DAR } \\
\text { remedio, consuelo, un consejo. Ordinare, } \\
\text { apponere. }\end{array}$ \\
\hline
\end{tabular}

Estas intervenciones se suman a la supresión de las citas del primer $D R A E$, lo que da lugar a un notable cambio en la configuración de las entradas desde Autoridades hasta la última edición del siglo XVIII, como se evidencia en esta otra acepción de dar ya mencionada, en la que la nota sintáctico-semántica y los ejemplos real e inventado se resuelven en un breve ejemplo que ilustra las dos construcciones que se mencionaban en Autoridades:

\begin{tabular}{|c|c|c|}
\hline Diccionario de autoridades & DRAE 1780 & DRAE 1791 \\
\hline $\begin{array}{l}\text { DAR. Vale tambien cascár, } \\
\text { golpeár, apaleár, castigár, } \\
\text { herir: como Dár de azótes, de } \\
\text { golpes, de palos, de heridas, } \\
\text { de estocadas. Y tambien } \\
\text { se puede usar poniendo el } \\
\text { instrumento de la pena o } \\
\text { castigo en acusativo: como } \\
\text { Dár azótes, \&c. Lat. Percutere. } \\
\text { Tundere. Ferire. Quev. Tacañ. } \\
\text { cap. 20. Cierra conmigo uno } \\
\text { de los dos... y con un garróte } \\
\text { dame dos palos en las piernas } \\
\text { y derribame en el suelo, y llega } \\
\text { el otro y dame un trasquilón de } \\
\text { oréja á oréja. }\end{array}$ & $\begin{array}{l}\text { DAR. Vale tambien cascar, } \\
\text { golpear, apalear, castigar, herir, } \\
\text { como DAR de azotes, de golpes, } \\
\text { de palos, de heridas, de } \\
\text { estocadas. Y tambien se puede } \\
\text { usar poniendo el instrumento } \\
\text { de la pena, ó castigo en } \\
\text { acusativo, como DAR azotes, } \\
\text { \&c. } \text { Percutere, tundere, ferire. }\end{array}$ & $\begin{array}{l}\text { DAR. [...]. 2. Cascar, golpear } \\
\text { con palo, látigo \&c.; y así se } \\
\text { dice dar de palos, de azotes, } \\
\text { ó dar palos, azotes, \&c. } \\
\text { Percutere, ictum impingere. }\end{array}$ \\
\hline
\end{tabular}

\subsection{EI DRAE 1803}

El prólogo de la cuarta edición del diccionario académico admite que la revisión del Diccionario de autoridades había llegado hasta la letra $L$ e informa de que, atendiendo a los requerimientos recibidos, se habían incluido voces y correcciones en las letras siguientes. Los cambios de la cuarta edición, pues, son más representativos que los de las dos anteriores, aunque no difieren de los que se han mencionado en los epígrafes precedentes.

No es raro que se suprima parte de la información sobre el uso. La intervención puede consistir en su eliminación completa, como ocurre con la nota de ampliación paradigmática de miel de prima o en los ejemplos de la entrada maceta. 


\begin{tabular}{|c|c|}
\hline DRAE 1791 & DRAE 1803 \\
\hline $\begin{array}{l}\text { MIEL DE PRIMA. Se llama en los ingenios de azúcar la } \\
\text { porcion que va despidendo luego que se ha echado } \\
\text { en la forma para hacer el pilon. Vulgarmente y con } \\
\text { ménos propiedad la llaman MIEL de cañas. Succus } \\
\text { sacchari purgati primus. }\end{array}$ & $\begin{array}{l}\text { MIEL DE PRIMA. El primer licor que destila del } \\
\text { azúcar quando se cuaja en la forma. Succus } \\
\text { sacchari purgati primus. }\end{array}$ \\
\hline $\begin{array}{l}\text { MACETA. s. f. El tiesto en que se siembran las yerbas } \\
\text { y flores: y se llama tambien así el ramo que tiene } \\
\text { muchas flores juntas y apiñadas; y así se dice: MACETA } \\
\text { de claveles, de azucenas, \&c. [...] 4. La empuñadura, } \\
\text { ó parte posterior del taco del juego de los trucos; y } \\
\text { así se dice: jugar de MACETA, quando algunos que } \\
\text { son ménos diestros se convienen en tomar el taco } \\
\text { al reves, para dar á las bolas con mas facilidad... }\end{array}$ & $\begin{array}{l}\text { MACETA. s. f. El tiesto en que se siembran } \\
\text { yerbas y flores. Vas testaceum floribus } \\
\text { excolendis. } \\
\text { [...] } \\
\text { MACETA. La parte posterior del taco en el } \\
\text { juego de los trucos. Trudiculi capulus. }\end{array}$ \\
\hline
\end{tabular}

O puede ser una reducción parcial, como en los ejemplos que aparecen en una de las acepciones de mechón.

\begin{tabular}{|c|c|}
\hline DRAE 1791 & DRAE 1803 \\
\hline $\begin{array}{l}\text { MECHON. [...] 2. La porcion de hilos, ó hebras } \\
\text { separada de las otras; como: MECHón de cabellos, } \\
\text { de lana, \&c. y así se suele decir: le quitó la } \\
\text { barba á MEchONEs. Filorum, vel capillorum } \\
\text { fasciculus, vel peniculus. }\end{array}$ & $\begin{array}{l}\text { MECHON. La porcion de hilos, ó hebras separada } \\
\text { de las otras; como: MECHON de cabellos, de lana } \\
\text { \&c. Floccus, peniculus. }\end{array}$ \\
\hline
\end{tabular}

Estas supresiones no responden a una voluntad de eliminar la información sobre el uso del diccionario, sino más bien a la voluntad de perfeccionarlo - a diferencia de lo que había ocurrido con otros elementos, como la etimología o las citas-, pues paralelamente se añaden notas y ejemplos a acepciones ya existentes, como en ulcerar, con una nueva nota sintáctica que da cuenta de la construcción pronominal del verbo (hasta ese momento solo se recogía la transitiva) y dos ejemplos que ilustran ambas; o en modales, entrada en la que el cambio parece obedecer a la necesidad de ilustrar la peculiaridad morfológica que indica la también nueva marca gramatical: el género ambiguo del lema.

\begin{tabular}{|l|l|}
\hline \multicolumn{1}{|c|}{ DRAE 1791} & \multicolumn{1}{c|}{ DRAE 1803 } \\
\hline $\begin{array}{l}\text { ULCERAR. v. a. Corroer el humor alguna parte } \\
\text { blanda del cuerpo, causando úlcera. Ulcerare. }\end{array}$ & $\begin{array}{l}\text { ULCERAR. v. a. Causar el humor ácre y corrosivo } \\
\text { alguna úlcera. Úsase tambien como recíproco. } \\
\text { Así se dice: la destilacion ácre le ha ULCERADo el } \\
\text { pulmon, se le ha ULCERADo una pierna. }\end{array}$ \\
\hline $\begin{array}{l}\text { MODAL. [...] La accion particular y propia } \\
\text { de algun sugeto con que se hace reparar y se } \\
\text { singulariza entre los demas; y así se dice: fulano } \\
\text { tiene notables MODALES. Modus, proprietas. }\end{array}$ & $\begin{array}{l}\text { MODALES. s. amb. p. El modo de las acciones } \\
\text { tienternas de cada uno; y así se dice: fulano } \\
\text { proprietas. }\end{array}$ \\
\hline
\end{tabular}


Además, se incorporan entradas o acepciones nuevas que contienen notas y ejemplos; frecuentemente adjetivos relacionales, como mecánico, báquico y escurialense (estas dos últimas en el suplemento), pero también en sustantivos, como meada o, de nuevo en el suplemento, quarentena.

BÁQUICO, CA. adj. Lo que pertenece á Baco; como: furor BáQuico. Bachicus.

MECÁNICO, CA. adj. Lo que pertenece á la ciencia mecánica; como principios MeCánICOS, explicacion MECÁNICA. Ad ingenia et machinas pertinens.

ESCURIALENSE. adj. Lo que pertenece al real monasterio del Escorial; y así se dice: biblioteca ESCURIALENSE, códice ESCURIALENSE. Escurialensis.

MEADA. El sitio que moja, ó señal que hace en el suelo una meada; y así decimos: aqui hay una MEADA de gato, en esta pared hay una MEADA. Mictus.

QUARENTENA. s. f. met. La suspension en dar asenso á alguna cosa; y así decimos: esa noticia es preciso ponerla en QUARENTENa. Animi in asentiendo suspensio.

En el caso de lemas ya presentes en el diccionario con otras acepciones, como mecánico, meada o quarentena, solo las acepciones novedosas presentan ejemplo, lo que puede responder, por un lado, a una intención didáctica y, por otro, a la voluntad de fundamentar la adición.

Además de la adición y supresión de notas y ejemplos, también en el DRAE 1803 se atestigua la transformación de lemas complejos en un lema simple cuya definición se completa con una nota de uso, con un ejemplo o con ambos elementos. Un caso muy ilustrativo, por el protagonismo que en él adquiere la atención al uso, lo constituye el lema dar cogote ('caer de espaldas'), que en el DRAE 1803 es reemplazado por una nueva acepción de dar ('caer'). Esta sustitución conlleva, por una parte, la adición de dos ejemplos que ilustran la acepción general y, por otra, la incorporación de una nota de uso y tres ejemplos con combinaciones prototípicas (dar de cogote, de espaldas, de costillas) para presentar la construcción "dar de + parte del cuerpo".

\begin{tabular}{|l|l|}
\hline \multicolumn{1}{|c|}{ DRAE 1791} & \multicolumn{1}{c|}{ DRAE 1803} \\
\hline DAR DE COGOTE. f. Lo mismo que CAER DE & DAR. Lo mismo que DERRIBAR, CAER; como: DIó con él en \\
ESPALDAS. (s. v. cogote) & $\begin{array}{l}\text { tierra, DIó consigo en el suelo. Junto con la partícula } \\
\text { de y algunos substantivos denota el modo con que se } \\
\text { cae como DAR de cogote, DAR de espaldas, de costillas } \\
\text { \&c. }(s . \text { v. dar }) .\end{array}$ \\
\hline
\end{tabular}

Se confirma, por tanto, la conservación y aún acrecentamiento de los ejemplos y las notas de uso, aunque, en ocasiones, se producen abundantes cambios en su formulación. 


\section{EL DICCIONARIO USUAL EN LA PRIMERA MITAD DEL SIGLO XIX (1817- 1852)}

Nos ocuparemos en este epígrafe del examen de las notas de uso y los ejemplos en las ediciones a las que se dedica nuestro proyecto de investigación (1817-1852). Se registra en ellas un descenso notable en la ampliación de entradas con respecto a la edición precedente, verificable desde la quinta edición y en aumento progresivo hasta la séptima (DRAE 1837). Además, las tres primeras ediciones analizadas (DRAE 1817-DRAE 1832) comportan la supresión de entradas de variado tipo a la que posiblemente subyace un cambio en la concepción del diccionario más en la línea de un diccionario manual (Clavería, en prensa, 2020).

Si la quinta edición supuso una remodelación notable y significativa de múltiples aspectos del diccionario (Clavería y Freixas 2018), las dos ediciones siguientes se caracterizan por la eliminación de ciertos tipos de entradas, entre las que destacan las variantes antiguas, en el DRAE 1822 (Jiménez Ríos 2018b y 2018c), y los participios pasivos, en el DRAE 1832 (Jiménez Ríos 2019). La reducción de la nomenclatura va acompañada de un acortamiento de la información lexicográfica solo cuando el artículo lexicográfico resultaba demasiado extenso (DRAE 1822-1832). En general, las ediciones estudiadas en este apartado, exceptuando la quinta, no implican grandes cambios ni tampoco revisiones de gran calado.

\subsection{EI DRAE 1817}

Conlleva la quinta edición notables innovaciones en el diccionario. Estas van desde la aplicación de los cambios ortográficos derivados de la Ortografía de 1815 (Blanco 2018a y Terrón 2018) hasta una intensa enmienda de la definición (Blanco 2018b, Freixas 2018, Muñoz 2018), en especial en ciertas esferas del léxico especializado (Garriga 2018 y Gómez de Enterría 2018), y cambios de carácter metalexicográfico vinculados a la ordenación de las formas complejas (Buenafuentes 2018 y Paz 2018) y la marcación estilística y diacrónica (Azorín 2018 y Jiménez Ríos 2018a).

En los nuevos lemas y acepciones de la quinta edición se siguen introduciendo algunas informaciones de uso siguiendo el modo de proceder de las ediciones precedentes. Se ejemplifican usos traslaticios, como en adagio o alegro, cuyos ejemplos ilustran la extensión del significado que más adelante, en 1884 , dará lugar a una nueva acepción ${ }^{15}$ :

ADAGIO. s. m. Mús. Uno de los cinco movimientos fundamentales de la música, que equivale á moderado. Tambien se da este nombre á la composicion; y asi se dice que tocan ó cantan un ADAGIO. Modus temperatus in musicis. (Suplemento).

ALEGRO. s. m. Mús. Uno de los cinco movimientos fundamentales de la música, que equivale á vivo ó alegre. Tambien se da este nombre á la composicion; y asi se dice: tocan ó cantan un ALEGRo.

15 “Adagio. (Del ital. adagio.) m. Mús. Uno de los aires ó movimientos principales del ritmo musical: es lento. ॥ Mús. Composición musical, ó parte de ella, en este aire ó movimiento. Tocan ó cantan un ADAGIO" (DRAE 1884). 
Y también, de nuevo en el plano sintagmático, se ilustra el uso de alguna construcción mediante notas (á chuzos), mediante ejemplos (adentros) o mediante la concurrencia de ambos elementos (pendol y pormenor).

Á Chuzos. mod. adv. fam. En abundancia y con mucha fuerza é ímpetu. Úsase con los verbos llover, granizar \&c. (s. v. chuzo).

ADENTROS. s. m. p. En lo moral significa lo interior del ánimo, y así se dice: Juan habla bien de Pedro, aunque en sus adentros siente de otro modo. Interior a animi.

PENDOL. s. m. Náut. Operacion que hacen los marineros para limpiar los fondos de una embarcacion, cargando peso á una banda ó lado para que inclinándose ó tumbando descubra el fondo del costado opuesto para limpiarle. Úsase mas comunmente en plural en la frase dar PENDOLES.

PORMENOR. s. m. La reunion de circunstancias menudas y particulares de alguna cosa. Úsase tambien frecuentemente en plural, como no entro en los PORMENORES de esta accion.

Muy especialmente se consignan ejemplos — con frecuencia más de uno ${ }^{16}$ - en los adjetivos relacionales para mencionar los sustantivos con los que se combinan. El DRAE 1817 sigue, pues, la tendencia iniciada en Autoridades de ejemplificar este tipo de adjetivos, cuyas definiciones suelen ser crípticas también en los diccionarios actuales. Estos ejemplos correrán distinta suerte en las ediciones posteriores, suprimidos en unos casos y conservados, aunque reducidos, en otros.

AGRARIO, RIA. adj. Lo que pertenece al campo, como ley aGraria, asuntos AGrarios. Agraria.

MALABÁRICO. adj. Lo que pertenece á la costa de Malabar; y asi se dice: reino MALABÁRICO.

MORUNO, NA. adj. Lo perteneciente a la mauritania; y asi se dice: alfange Moruno, lengua MORUNA.

PINDÁRICO, CA. adj. Lo que pertenece á PÍNDARO ó á su estilo; y asi se dice: oda PINDÁRICA.

SIXTINO, NA. adj. Lo que pertenece a alguno de los papas llamados Sixtos, como capilla SIXTINA, bula SIXTINA.

De sumo interés resulta la información que atesora la voz ora, que aparece como lema en la quinta edición. En realidad, el uso de la conjunción discontinua figuró en los diccionarios académicos desde Autoridades hasta 1791, pero escrito con hache como acepción de hora. La entrada desaparece del diccionario en 1803 y se reincorpora totalmente reescrita bajo el lema ora con una extensa nota de información gramatical completada con dos ejemplos.

16 La única excepción que documentamos la constituye escurialense. V. infra. 


\begin{tabular}{|l|l|}
\hline \multicolumn{1}{|c|}{ Diccionario de autoridades } & \multicolumn{1}{|c|}{ DRAE 1817 } \\
\hline $\begin{array}{l}\text { HORA. adv. Contraccion de Ahóra, que sirve para } \\
\text { distribuir los extremos de una oración. Lat. Jam. }\end{array}$ & $\begin{array}{l}\text { ORA. adv. Lo mismo que YA. Sirve para } \\
\text { distinguir las cláusulas, y para señalar } \\
\text { Modò. Tum. PINT. Dial. part. 2. Dial. 1. cap. 8. Aquel } \\
\text { perfectamente las acciones y objetos, } \\
\text { es prudente que tiene el medio en las cosas, y que en el } \\
\text { discurso de su vida puede sufrir todo lo que le sucede, } \\
\text { con ánimo quieto y constante, hora sea próspero, } \\
\text { gora adverso. PelLic. Argen. part. 1. lib. 1. f. 7. Hora } \\
\text { gigantes, ora vestiglos. } \\
\text { sacrifique à los Dioses, hora en la mesa le convide la } \\
\text { alegría, no ciñe su frente sino con el sagrado ramo de } \\
\text { la olíva. }\end{array}$ \\
\hline
\end{tabular}

El segundo de los ejemplos del DRAE 1817 es una ilustrativa muestra de lo que autores como Quemada (1968: 505) llaman reminiscencias, elementos que están en el límite entre cita y ejemplo en cuanto que, aunque se incorporan como cualquier ejemplo inventado, parafrasean un texto conocido - en este caso, del Quijote, obra muy presente en el diccionario desde Autoridades - : “... más alcanzan con Dios dos docenas de diciplinas que dos mil lanzadas, ora las den a gigantes, ora a vestiglos o a endriagos" (Quijote, II [CORDE]) ${ }^{17}$. En cuanto a la enmienda, en esta edición se produce una intensa revisión de la definición (Freixas 2018), lo que, en algún caso, trae aparejada la eliminación de notas y ejemplos de uso, como puede observarse en adversativo o valentía:

\begin{tabular}{|c|c|}
\hline DRAE 1803 & DRAE 1817 \\
\hline $\begin{array}{l}\text { ADVERSATIVO, VA. adj. Gram. que } \\
\text { comunmente se usa en la terminacion femenina, } \\
\text { y se aplica á aquella partícula que distingue en } \\
\text { una clausula la segunda parte de la primera, } \\
\text { realzando, ó minorando el sentido de ella, como } \\
\text { son en castellano las partículas PERO, MAS, y } \\
\text { otras semejantes: v. g. La casa es pequeña, } \\
\text { PERo hermosa: Alexandro fué valeroso, PERo } \\
\text { iracundo. Particula, vel oratio adversativa. }\end{array}$ & $\begin{array}{l}\text { ADVERSATIVO, VA. Gram. adj. que } \\
\text { comunmente se usa en la terminacion femenina, } \\
\text { y se aplica á aquellas partículas que expresan } \\
\text { alguna oposicion y contrariedad entre lo que } \\
\text { se ha dicho y lo que se pasa á decir. Particulae } \\
\text { adversativae. }\end{array}$ \\
\hline $\begin{array}{l}\text { VALENTÍA. La accion de esfuerzo, ó vigor que } \\
\text { excede á las fuerzas naturales, por el estado en } \\
\text { que se halla el que las executa; y así se dice: que } \\
\text { el enfermo ha hecho una valentía saliendo de } \\
\text { casa. Actus ultra vires. }\end{array}$ & $\begin{array}{l}\text { VALENTÍA. La accion esforzada y vigorosa que } \\
\text { parece exceder á las fuerzas naturales. Actus } \\
\text { ultra vires. }\end{array}$ \\
\hline
\end{tabular}

No puede decirse, sin embargo, que la supresión de la información sobre el uso sea una tendencia de esta edición, pues la revisión de las definiciones también puede implicar la modificación de un ejemplo para convertirlo en nota de uso (s. v. cuarentena) o la adición de ejemplos (como en in prontu, entrada que se reincorpora después de haber desaparecido en 1803).

17 Cfr. Terreros, s. v. ora, con reproducción de la cita. 


\begin{tabular}{|l|l|}
\hline \multicolumn{1}{|c|}{ DRAE } & \multicolumn{1}{c|}{ DRAE 1817} \\
\hline $\begin{array}{l}\text { QUARENTENA. s. f. met. La suspension en dar } \\
\text { asenso á alguna cosa; y asi decimos: esa noticia } \\
\text { es preciso ponerla en QUARENTENA. Animi in } \\
\text { asentiendo suspensio. (DRAE 1803, suplemento). }\end{array}$ & $\begin{array}{l}\text { CUARENTENA. s. f. met. Suspension del asenso } \\
\text { tiempo para asegurarse de su certidumbre. Úsase } \\
\text { comunmente con los verbos poner, pasar y } \\
\text { otros. (Suplemento). }\end{array}$ \\
\hline $\begin{array}{l}\text { IN PROMPTU. mod. adv. Tomado del latin, que } \\
\text { se usa del mismo modo en nuestro castellano, } \\
\text { y significa lo mismo que PRONTAMENTE, ó AL } \\
\text { PRESENTE. (DRAE 1791). }\end{array}$ & $\begin{array}{l}\text { IN PRONTU. f. ant. puramente latina que se } \\
\text { aplica á las cosas que estan á la mano; y asi se } \\
\text { dice tener una cosa IN PRONTU. In promtu habere. }\end{array}$ \\
\hline
\end{tabular}

Cuarentena es una buena muestra de la permanente revisión a la que se someten las entradas, pues, como se indicaba en el apartado anterior, era un lema nuevo de la cuarta edición del diccionario. Se verifican asimismo cambios en el adjetivo escurialense, adición del suplemento de 1803 que figuraba con dos ejemplos (biblioteca escurialense, códice escurialense) y que pasa al volumen de 1817 solo con el primero de ellos.

\subsection{EI $D R A E 1822$}

Las ediciones de 1822 y 1832 implican un cambio sustancial en el diccionario; no tanto por la ampliación léxica, que se ve reducida ostensiblemente, sino por la supresión tanto de entradas - fundamentalmente de formas anticuadas - como de parte de la información que aparece dentro de ellas. Aparte del escaso aumento y la supresión de lemas y acepciones, la información lexicográfica de las nuevas entradas de la sexta edición es también distinta, pues en ellas se percibe, en general, poca precisión lexicográfica y una acusada tendencia a la definición sinonímica. En relación con esta última, es destacable el hecho de que, como reflejo del afán de acortamiento que preside la enmienda, se eliminen las fórmulas que introducen la remisión a otro lema, variante o sinónimo (lo mismo que, véase...), heredadas de Autoridades, para consignar simplemente el lema al que se remite, que aparecerá en versalita (Pascual Fernández 2018). Se trata de una innovación notable de esta edición que puede considerarse un paso más en el proceso de formalización que van experimentando las entradas del diccionario.

\begin{tabular}{|l|l|}
\hline \multicolumn{1}{|c|}{ DRAE 1817} & \multicolumn{1}{c|}{ DRAE 1822} \\
\hline PALPADURA. s. f. Lo mismo que PALPAMIENTO. & PALPADURA. s. f. PALPAMIENTO. \\
\hline SACRAMENTO. Lo mismo que MISTERIO. & SACRAMENTO. MISTERIO. \\
\hline
\end{tabular}

A diferencia de las notas del aumento de 1817, que suponen una ampliación sintagmática, en los lemas nuevos de la sexta edición se ofrece exclusivamente información sinonímica (ampliación paradigmática), como puede observarse en estas tres adiciones del suplemento:

ABDOMEN. s. m. Anat. Cavidad del tronco humano, que encierra y oculta á la vista las principales entrañas del cuerpo, y está situada debajo del pecho y encima de las extremidades inferiores. Comunmente se llama bajo vientre. Abdomen. 
ARTOLAS. s. f. p. Aparejo que se usa en la Rioja, Navarra y provincias Vascongadas, en forma de dos silletas atadas con una cuerda y colocadas cada una al lado de la caballería, en la que viajan dos personas con mucha comodidad en el movimiento. En algunas partes se Ilaman CARTOLAS.

Además, aparecen ejemplos en algún adjetivo relacional, como cereal, oral y pecuario, y de algunas construcciones, como en irrogar y monises.

CEREAL. adj. c. Lo que pertenece á la diosa Ceres; y asi se llamaban fiestas cereales las que se hacían en honor suyo.

ORAL. adj. Lo que se expresa por sola la palabra, como tradicion oraL.

PECUARIO, RIA. adj. Lo que pertenece á los ganados; y asi se dice: leyes PECUARIAs.

IRROGAR. v. a. Causar, ocasionar; y asi se dice: le irrogó un gran perjuicio.

MONISES. p. En sentido vulgar moneda ó dinero; y asi se dice: F. trae ó tiene MONISES.

Como se ha señalado, la sexta edición del $D R A E$ comporta también el acortamiento de las entradas en un intento de conseguir un diccionario "más manejable" y, en consecuencia, más breve. En el terreno de los ejemplos esta tendencia puede provocar su reducción, como ocurre en el caso del adjetivo agrario o del verbo averiguar, pero no documentamos una actuación especialmente significativa en este sentido.

\begin{tabular}{|c|c|}
\hline DRAE 1817 & $D R A E 1822$ \\
\hline $\begin{array}{l}\text { AGRARIO, RIA. adj. Lo que pertenece al campo, } \\
\text { como ley AGRARIA, asuntos AGRARIos. Agraria. }\end{array}$ & $\begin{array}{l}\text { AGRARIO, RIA. adj. Lo que pertenece al campo, } \\
\text { como ley AGRARIA. Agrarius. }\end{array}$ \\
\hline $\begin{array}{l}\text { AVERIGUARSE CON ALGUNO. f. fam. Avenirse con } \\
\text { alguno, sujetarle ó reducirle á la razon; y asi } \\
\text { se dice: no hay quien SE AVERIGÜE CON ÉL: No } \\
\text { ME PUEDO AVERIGUAR con este muchacho \&c. } \\
\text { Aliquem ad justum redigere, rationi subjicere. }\end{array}$ & $\begin{array}{l}\text { AVERIGUARSE CON ALGUNO. f. fam. Avenirse con } \\
\text { alguno, sujetarle ó reducirle á la razon; y asi } \\
\text { se dice: no hay quien SE AVERIGÜE CON ÉL \&c. } \\
\text { Aliquem ad justum redigere, rationi subjicere. }\end{array}$ \\
\hline
\end{tabular}

\subsection{El DRAE 1832}

La séptima edición del diccionario, como la anterior, estuvo presidida por una tendencia preponderante a la reducción. La mejor ilustración de este empeño se encuentra tanto en la eliminación de artículos, fundamentalmente los participios pasivos, como en la eliminación de entradillas claramente diferenciadas para las acepciones y las formas complejas.

Aunque básicamente se mantiene, como en las ediciones anteriores, la forma de introducir las notas y ejemplos de uso en el discurso lexicográfico, se produce un leve cambio en la fórmula introductoria úsase, que en el DRAE 1832 empieza a ser sustituida, aunque no de forma sistemática, por se $u s a^{18}$.

18 Como ya hemos apuntado, se mantiene de este modo hasta la duodécima edición (DRAE 1884) cuando las notas de uso se acortan mediante el empleo de abreviaturas. 


\begin{tabular}{|c|c|}
\hline DRAE 1822 & DRAE 1832 \\
\hline $\begin{array}{l}\text { TRASCURSO. s. m. La carrera del tiempo } \\
\text { ó continuacion sucesiva de los tiempos que } \\
\text { pasan. Úsase comunmente con la misma voz } \\
\text { tiempo. Transcursus temporis. }\end{array}$ & $\begin{array}{l}\text { TRASCURSO. s. m. La carrera del tiempo ó } \\
\text { continuacion sucesiva de los tiempos que pasan. } \\
\text { Se usa comunmente con la misma voz tiempo. } \\
\text { Transcursus temporis. }\end{array}$ \\
\hline
\end{tabular}

El aumento de lemas nuevos es aún más limitado que en la edición precedente y en las definiciones de estos no se documentan notas de uso o ejemplos. De forma paralela, en la enmienda, la reducción se percibe tanto en la eliminación completa de los ejemplos (como en abacial, adagio, moderadamente, escurialense, malabárico o pecuario) como en la disminución de su número (máquina, meada, mecánico, médico, monises o moruno). Se muestran a continuación algunas de estas entradas:

\begin{tabular}{|c|c|}
\hline DRAE 1822 & DRAE 1832 \\
\hline $\begin{array}{l}\text { ABACIAL. adj. Lo que pertenece al Abad, como: } \\
\text { celda ABACIAL. Abbatialis, sive ad Abbatem } \\
\text { pertinens. }\end{array}$ & $\begin{array}{l}\text { ABACIAL. adj. Lo que pertenece al abad. } \\
\text { Abbatialis, sive ad abbatem pertinens. }\end{array}$ \\
\hline $\begin{array}{l}\text { ADAGIO. s. m. Mús. Uno de los cinco } \\
\text { movimientos fundamentales de la música, que } \\
\text { equivale á moderado. Tambien se da este nombre } \\
\text { á la composicion; y asi se dice que tocan ó } \\
\text { cantan un ADAGIO. Modus temperatus in musicis. }\end{array}$ & $\begin{array}{l}\text { ADAGIO. m. [...] \| Mús. Uno de los cinco } \\
\text { movimientos fundamentales de la música, que } \\
\text { equivale á moderado. Tambien se da este nombre } \\
\text { á la composición. Modus temperatus in musicis. }\end{array}$ \\
\hline $\begin{array}{l}\text { MODERADAMENTE. Mediana y razonablemente; } \\
\mathbf{y} \text { asi se dice: fulano hizo tal funcion } \\
\text { MODERADAMENTE. Modicè, mediocriter, }\end{array}$ & $\begin{array}{l}\text { MODERADAMENTE. }[\ldots] \text { Mediana } \\
\text { razonablemente. Modicè, mediocriter, }\end{array}$ \\
\hline $\begin{array}{l}\text { MÁQUINA. met. Multitud y abundancia; y asi se } \\
\text { dice: hubo una gran MÁQUINA de gente, tengo } \\
\text { una MÁQuiNA de libros. Multitude. }\end{array}$ & $\begin{array}{l}\text { MÁQUINA. met. fam. }[\ldots] \text { Multitud y } \\
\text { abundancia; } \mathbf{y} \text { asi se dice: tengo una MÁQUINA DE } \\
\text { LIBRos. Multitude }\end{array}$ \\
\hline $\begin{array}{l}\text { MÉDICO, CA. adj. Lo que toca ó pertenece á } \\
\text { la medicina, como ciencia MÉDICA, término } \\
\text { MÉDICo. Medicus. }\end{array}$ & $\begin{array}{l}\text { MÉDICO, CA. adj. Lo que toca ó pertenece á la } \\
\text { medicina, como ciencia MÉDICA. Medicus. }\end{array}$ \\
\hline
\end{tabular}

Cabe notar, además, que se perciben algunos cambios tipográficos en la edición que resultan inconsecuentes con el criterio aplicado en el resto del diccionario. Se documenta, por ejemplo, el uso de la cursiva para destacar el lema ejemplificado en fiestas cereales ( $s$. v. cereal) o los sinónimos de abdomen y artolas, cuando lo habitual en estos casos venía siendo la versalita.

\subsection{EI DRAE 1837}

También es de exiguo calado el aumento y la corrección que conlleva la enmienda del DRAE 1837; gran parte de la adición de lemas se encuentra en el suplemento (Clavería, 2016: 109, 111). En el aumento de entradas se registra algo más de actividad a la hora 
de incorporar notas y ejemplos que en la edición anterior. Como en la sexta edición, se presentan notas de ampliación paradigmática; en un caso, para introducir variantes (cachamarin, en el suplemento) y, en otro, sinónimos (convólvulo), contraviniendo la tendencia que se había ido generalizando de no mencionar estos segmentos en el artículo correspondiente a la entrada preferida. Especialmente llamativa es la presencia de la información sinonímica en la entrada convólvulo:

CACHAMARIN ó CAHEMARIN. m. Embarcacion chica de dos palos, con velas al tercio, algunos foques en un botalon á proa, y gavias volantes en tiempos bonancibles. Úsase en las costas de Bretaña y en la de Cantabria, donde tambien se llama Quechemarin.

CONVÓLVULO. m. Gusanillo que destruye las vides y se envuelve en sus hojas, llamado tambien revolton. Convolvolus. "I Yerba llamada tambien clemátide, dafnoíde, vincaperrinca, voluble. \& c. Convolvolus.

Tienen notas de ampliación sintagmática que proporcionan información sintáctica o semántica acollonar y engrescar (ambas adiciones del suplemento con una nota sobre el uso recíproco del verbo), así como remitente y veintiun.

ACOLLONAR. a. ACORBARDAR. Úsase tambien como recíproco.

REMITENTE. p. a. Lo que remite. Aplícase á la calentura que va perdiendo su fuerza sin llegarse á extinguir, y vuelve á tomar aumento.

VEINTIUN. adj. Veintiuno. Se antepone siempre al sustantivo.

Son ejemplo de nuevas acepciones con ejemplos adelantar y rayar, ambas del suplemento.

ADELANTAR. n. Progresar en estudios, robustez, medras. Así decimos; este niño está muy ADELANTADO: el convaleciente no ADELANTA nada.

RAYAR (el SOL) [...] n. Amanecer, apuntar la luz. Así se dice: RAYABa el alba, el dia. Lucescere.

A diferencia de ediciones anteriores y, como se verá, posteriores, en el DRAE 1837 no se suelen incorporar ejemplos a los nuevos adjetivos relacionales (cerebral, atentatorio, constitucional, continental, crepuscular, imitativo, teutónico...). Solo imitativo completa su definición con ejemplos:

IMITATIVO. adj. Lo perteneciente á la imitación; como artes imitativas, armonía imitativa.

Constituye una excepción a los esquemas definitorios y de introducción de la información sobre el uso que se han ido fijando en las sucesivas ediciones esta nueva acepción del adjetivo fresco, agregada en el suplemento de 1837 :

FRESCO, CA. Con los verbos estar, quedar, se usa en sentido irónico: ESTÁ VD. FRESCO; HEMOS QUEDADO FRESCOS indica estar ó quedar mal en algun negocio ó disputa. 
Se desdibujan aquí los límites entre definición y nota y ejemplos, volviéndose en cierto modo al ejemplo-explicación (o definición-explicación) de Autoridades.

Por último, en el ámbito de la enmienda, cabe destacar que en el DRAE 1837 se observa una tendencia al uso de punto y coma para separar ejemplos ( $s$. v. ora), definiciones y ejemplos (s. v. oral) o notas y ejemplos (s. v. pormenor). Se sustituyen por ese signo las comas o los dos puntos como delimitadores de dichos elementos. El cambio mejora la legibilidad de la información, lo que se hace evidente en la separación de los dos ejemplos que ilustran el uso de ora en la construcción distributiva.

\begin{tabular}{|l|l|}
\hline \multicolumn{1}{|c|}{ DRAE 1832 } & \multicolumn{1}{|c|}{ DRAE 1837 } \\
\hline $\begin{array}{l}\text { ORA. conj. YA. Sirve para distinguir las cláusulas, } \\
\text { y para señalar perfectamente las acciones y } \\
\text { objetos; como oRA digas, ORA leas, ORA sean } \\
\text { gigantes, ORA véstiglos. Vel. }\end{array}$ & $\begin{array}{l}\text { ORA. conj. YA. Sirve para distinguir las cláusulas, } \\
\text { para señalar perfectamente las acciones y } \\
\text { objetos, como orA digas, ORA leas; oRA sean } \\
\text { gigantes, ORA vestiglos. Vel. }\end{array}$ \\
\hline
\end{tabular}

\subsection{EI DRAE 1843}

Solo cinco años después de la octava, la novena edición refleja un crecimiento del aumento de lemas con respecto a las ediciones inmediatamente anteriores (DRAE 1822-1837); a la par, se produce cierta revitalización de la atención al uso en el aumento de lemas. Varias notas proporcionan información léxico-semántica, pues se refieren a contornos y presentan algún sinónimo:

ARGENTÍFERO. adj. Lo que contiene plata: dícese de los minerales.

LUCIDEZ. f. Claridad; Se aplica á los escritos ó discursos.

LURTE. m. pr. Arag. La masa de nieve que suele desprenderse de las cumbres, y caer á los valles, á la cual en otros puntos de la misma prov. llaman ALud.

No obstante, lo más destacado en el aumento es la incorporación de un buen número de adjetivos, la mayoría de ellos relacionales y muchos propios del lenguaje científico-técnico, una cuestión planteada en el interesante prólogo de la novena edición (Clavería 2016: 115 122). En estas entradas se retoma la práctica de insertar ejemplos con agrupaciones sintagmáticas prototípicas. Son adjetivos nuevos del diccionario, todos con uno o dos ejemplos, asainetado, barométrico, centígrado, cobratorio, gástrico, indagatorio, manufacturero, masónico, novelesco, reglamentario y sanitario.

ASAINETADO, DA. Lo que es parecido al sainete; v. g. comedia asainetada.

BAROMÉTRICO, CA. adj. Lo perteneciente al barómetro; como escala barométrica.

GÁSTRICO, CA. Med. adj. que se aplica á algunas cosas pertenecientes al estómago; como jugos gástricos, fiebre gástrica. 
NOVELESCO, CA. adj. Lo que es propio de novelas, como lance novelesco imaginacion NOVELESCA.

REGLAMENTARIO, RIA. adj. Lo perteneciente á reglamento; como disposicion reglamentaria.

SANITARIO, RIA. adj. Lo concerniente á la sanidad; como, medidas sanitarias.

Como se ve en esta muestra, los ejemplos de los nuevos lemas eligen la fórmula introductoria más breve, como — salvo asainetado, cuyo ejemplo va encabezado por la abreviatura $v . g$.- , a diferencia de lo atestiguado en ediciones anteriores, en cuyo aumento alternaban las fórmulas (y) así se dice y como. Se observa también la convivencia de tipografías distintas en los ejemplos (redonda y versalita).

En lo que a la enmienda se refiere, se documentan varios casos de intervención en las notas y ejemplos que intentan mejorar los artículos. Es lo que ocurre en la entrada del lema complejo esa es grilla (s. v. grilla), en la que la presencia del ejemplo, coincidente con el lema, resultaba redundante.

\begin{tabular}{|l|l|}
\hline \multicolumn{1}{|c|}{ DRAE 1837} & DRAE 1843 \\
\hline $\begin{array}{l}\text { ESA ES GRILLA. expr. del estilo familiar, en el } \\
\text { cual para dar á entender que se duda de alguna } \\
\text { especie que se oye se suele decir: ESA ES GRILLA. } \\
\text { Nugas agis. (s. v. grilla) }\end{array}$ & $\begin{array}{l}\text { ESA ES GRILLA. expr. del estilo familiar, para } \\
\text { dar á entender que se duda de alguna especie que } \\
\text { se oye. Nugas agis. (s. v. grilla) }\end{array}$ \\
\hline
\end{tabular}

Del mismo modo, resulta pertinente la enmienda que se lleva a cabo en el lema y el ejemplo de rayar que se había incorporado en el suplemento de la edición anterior. La combinación rayar el sol pasa a consignarse en un ejemplo - y no como lema- junto a rayar el día o rayar el alba. Nótese que, además, en consonancia con lo apuntado en el aumento, la fórmula introductoria así se dice también se modifica.

\begin{tabular}{|l|l|}
\hline \multicolumn{1}{|c|}{$D R A E 1837$} & \multicolumn{1}{|c|}{ DRAE 1843 } \\
\hline $\begin{array}{l}\text { RAYAR (EL SOL). [...] n. Amanecer, apuntar la luz. Así } \\
\text { se dice: rayaba el alba, el dia. } \text { Lucescere. }\end{array}$ & $\begin{array}{l}\text { RAYAR. [...] Apuntar la luz: como } \\
\text { RAYABA el sol, el dia, el alba etc. } \text { Lucere. }\end{array}$ \\
\hline
\end{tabular}

Mencionaremos, por último, el caso de cereal, en cuya primera acepción se modifica el tiempo verbal de la fórmula introductoria (asi se llamaban > así se llaman), dado que el hecho de que el referente (las fiestas cereales) sea un acontecimiento histórico no implicaba necesariamente que la denominación no tuviera vigencia.

\begin{tabular}{|l|l|}
\hline \multicolumn{1}{|c|}{ DRAE 1837} & \multicolumn{1}{c|}{ DRAE 1843 } \\
\hline $\begin{array}{l}\text { CEREAL. adj. c. Lo que pertenece á la diosa } \\
\text { Ceres; } \mathbf{y} \text { asi se llamaban fiestas cereales las } \\
\text { que se hacian en honor suyo. }\end{array}$ & $\begin{array}{l}\text { CEREAL. adj. c. Lo que pertenece á la diosa } \\
\text { Céres; y asi se llaman fiestas cereales las que se } \\
\text { hacian en honor suyo. }\end{array}$ \\
\hline
\end{tabular}

Se corrigen además algunas erratas de las notas y ejemplos de la edición anterior, como 
vincaperrinca > vincapervinca (s. v. convólvulo) o la letra redonda, que pasa a ser versalita, en artes imitativas, armonía imitativa (s. v. imitativo). Pero la intervención en los artículos también da lugar a nuevas erratas, como en péndol, donde puede haberse suprimido por error el verbo dar en el ejemplo o bien se ha mantenido erróneamente el ejemplo tras la nota "se usa mas comunmente en plural"19.

\begin{tabular}{|c|c|}
\hline DRAE 1837 & $D R A E 1843$ \\
\hline $\begin{array}{l}\text { PÉNDOL. s. m. Náut. Operacion que hacen } \\
\text { los marineros para limpiar los fondos de una } \\
\text { embarcacion, cargando peso á una banda ó lado, } \\
\text { para que inclinándose ó tumbando descubra el } \\
\text { fondo del costado opuesto para limpiarle. Se usa } \\
\text { mas comunmente en plural en la frase dar } \\
\text { PÉNDOLES... }\end{array}$ & $\begin{array}{l}\text { PÉNDOL. s. m. Náut. Operacion que hacen } \\
\text { los marineros para limpiar los fondos de una } \\
\text { embarcacion, cargando peso á una banda } \\
\text { ó lado, para que inclinándose ó tumbando } \\
\text { descubra el fondo del costado opuesto para } \\
\text { limpiarle. Se usa mas comunmente en plural } \\
\text { en la frase PÉNDOLES... }\end{array}$ \\
\hline
\end{tabular}

Por otra parte, la reescritura de la definición de abdomen trae aparejada la supresión de la mención al sinónimo bajo vientre — se elimina, pues, la nota de ampliación paradigmática-, mientras que en otras ocasiones, como en la segunda acepción de cereal, se añade información, en este caso de carácter gramatical.

\begin{tabular}{|l|l|}
\hline \multicolumn{1}{|c|}{ DRAE 1837} & \multicolumn{1}{|c|}{ DRAE 1843 } \\
\hline $\begin{array}{l}\text { ABDÓMEN. s. m. Anat. Cavidad del tronco humano, } \\
\text { que encierra y oculta á la vista las principales } \\
\text { entrañas del cuerpo, y está situado debajo del } \\
\text { pecho y encima de las extremidades inferiores. } \\
\text { Comunmente se llama bajo vientre. Abdomen. }\end{array}$ & $\begin{array}{l}\text { ABDÓMEN. m. Anat. Cavidad del tronco } \\
\text { humano, situada debajo del pecho y encima } \\
\text { de las extremidades inferiores. Abdomen. }\end{array}$ \\
\hline $\begin{array}{l}\text { CEREAL. adj. c. [...] Se aplica á las plantas ó frutos } \\
\text { farináceos; como el trigo, centeno, cebada \&c. }\end{array}$ & $\begin{array}{l}\text { CEREAL. adj. c. Se aplica á las plantas ó } \\
\text { frutos farináceos; como el trigo, centeno, } \\
\text { cebada \&c. En este caso se usa como } \\
\text { sustantivo. }\end{array}$ \\
\hline
\end{tabular}

\subsection{EI DRAE 1852}

A mediados del siglo XIX ve la luz pública la décima edición del diccionario y con ella concluye nuestro estudio. Se trata de una nueva versión de la obra en la que el aumento de lemas supera la edición inmediatamente precedente, pero no alcanza la cifra de la ya lejana quinta edición. La décima edición supone una enmienda parcial del diccionario, pero conlleva cambios de cierto calado (Clavería 2016, Clavería, en prensa).

La atención al uso en el aumento del DRAE 1852 resulta más interesante que en la edición precedente, no solo porque se mantiene la tendencia a la revitalización iniciada en esta, en especial en lo que a las notas se refiere, sino por el resurgir de las notas sintagmáticas que atienden a aspectos sintácticos, prácticamente inexistentes en el aumento de las ediciones anteriores. Así, se señalan particularidades nominales como el uso sustantivo de debilitante, locomotor y ricote:

19 De hecho, en el DRAE 1869 tras dicha nota no aparece ningún ejemplo. 
DEBILITANTE. p. a. de DEBILITAR. Lo que debilita. Úsase tambien como sustantivo en la medicina.

LOCOMOTOR, RA. adj. Lo que produce y ocasiona el movimiento de traslacion en algunas máquinas. Se usa tambien como sustantivo en ambas terminaciones.

RICOTE. adj. aum. de RICO. Úsase comunmente como sustantivo masculino y suele ser voz despreciativa.

En el ámbito verbal se hace referencia a las características de uso de los verbos, como la posibilidad de construirlos como recíprocos (enorgullecer, horripilar, oxidar, paralizar y tazar) o activos (cosechar). Se trata de un tipo de información que, desde el Diccionario de autoridades 1770 , va incluyéndose progresivamente ${ }^{20}$ :

COSECHAR. n. Hacer la cosecha. Úsase tambien como activo en la significacion de cojer ó colectar los frutos.

ENORGULLECER. a. Llenar de orgullo, hinchazon ó soberbia. Superbiam efferre, excitare. Úsase mas comunmente como recíproco.

HORRIPILAR. a. fam. Hacer que se ericen los cabellos, causar horror y espanto. Se usa ordinariamente como recíproco.

OXIDAR. a. Reducir un cuerpo al estado de óxido. Se usa tambien como recíproco.

PARALIZAR. a. Causar parálisis. Úsase tambien como recíproco.

TAZAR. a. Rozar la ropa por los dobleces. Úsase comunmente como recíproco.

En la forma compleja a la bartola se indican los verbos con los que se suele combinar:

BARTOLA (Á LA). Loc. fam. Sin ningun cuidado. Úsase con los verbos echarse y tenderse.

Las notas de uso no son exclusivamente sintácticas, pues en el caso de reñidero se precisa el ámbito semántico en el que se suele utilizar el término:

REÑIDERO. m. Sitio destinado á la riña de algunos animales. Aplícase principalmente á la de los gallos.

En el terreno de los ejemplos, los adjetivos relacionales, que siempre aparecen resaltados en versalita, son de nuevo los protagonistas:

AGRÍCOLA. adj. que se aplica á cosas relativas al cultivo del campo, como INDUSTRIA AGRÍCOLA.

DESPRECIATIVO, VA. Lo que indica desprecio, como tono DESPRECIATIVo.

20 Y se añade también en esta edición en algunos verbos, como puede observarse en inficionar y fracturar. 
FIGULINO, NA. adj. que se aplica á las cosas hechas de barro cocido, como estatua FIGULINA ${ }^{21}$.

LEGUMINOSO, SA. adj. Lo que se parece á las legumbres en sus propiedades: como plantas LEGUMINOSAS.

PERICIAL. adj. Lo perteneciente á los peritos, como juicio PERICIAL, tasacion PERICIAL.

QUERSONESO. m. Península, como el QUERSONESo címbrico, áureo, etc. Chersonesus.

SINÓPTICO, CA. adj. Lo que á primera vista presenta con claridad y distincion las partes principales de un todo; como, cuadro sinóPTICo, tabla sinóPTICA.

El ejemplo como apoyo de la definición y con la fórmula introductoria "así se dice" continúa utilizándose en el aumento de lemas, como puede observarse en minoría:

MINORÍA. f. En las juntas, asambleas, etc. el conjunto de votos dados en contra de lo que opina el mayor número de los votantes: así se dice: tal proposicion tuvo tantos votos de MinoRía. || La fraccion de un cuerpo deliberante que de ordinario vota contra el mayor número de sus individuos; así se dice: N. pertenece á la MINORía.

En el campo de la enmienda, cabe señalar que, aunque la práctica de resaltar el lema ejemplificado en versalita dentro de los ejemplos se venía documentando en ediciones anteriores, este cambio tipográfico se hace más evidente en 1852 (asainetado, barómetrico, cobratorio, gástrico, indagatorio, masónico...) con lo que el diccionario gana en homogeneidad tipográfica.

\begin{tabular}{|l|l|}
\hline \multicolumn{1}{|c|}{$D R A E 1843$} & \multicolumn{1}{|c|}{ DRAE 1852} \\
\hline $\begin{array}{l}\text { INDAGATORIO, RIA. adj. for. Lo que conduce } \\
\text { á la averiguacion de un hecho, como declaracion } \\
\text { indagatoria. }\end{array}$ & $\begin{array}{l}\text { INDAGATORIO, RIA. adj. for. Lo que conduce } \\
\text { á la averiguacion de un hecho, como declaracion } \\
\text { INDAGATORIA. }\end{array}$ \\
\hline $\begin{array}{l}\text { SUSTANCIA. f. [...] El valor y estimacion que } \\
\text { tienen las cosas, por el cual deben ser graduadas; } \\
\text { como hombre ó negocio de sustancia... }\end{array}$ & $\begin{array}{l}\text { SUSTANCIA. f. [...] El valor y estimacion que } \\
\text { tienen las cosas, por el cual deben ser graduadas; } \\
\text { como hombre ó negocio de suSTANCIA... }\end{array}$ \\
\hline
\end{tabular}

El proceso de enmienda de la décima edición respeta en general los ejemplos y notas de uso existentes en el diccionario ${ }^{22}$ y aún intenta su mejora o ampliación cuando la entrada es objeto de revisión, algo que puede observarse en la adición de información gramatical en el caso de irrogar, zarpar e in prontu, en este caso paralela a la revisión de la definición.

21 La entrada se encontraba ya en el Diccionario de autoridades, hasta el DRAE 1783, pero sin ejemplo de uso; la décima edición la recupera e incorpora la ejemplificación tan típica de los adjetivos relacionales.

22 Ocasionalmente puede suprimirse el ejemplo cuando existe una reforma de la información lexicográfica (cfr. no ser sin misterio ó no ser por falta de misterio, s. v. misterio). 


\begin{tabular}{|l|l|}
\hline \multicolumn{1}{|c|}{$D R A E 1843$} & \multicolumn{1}{c|}{ DRAE 1852} \\
\hline $\begin{array}{l}\text { IN PRONTU. expr. ant. y puramente latina que } \\
\text { se aplica á las cosas que están á la mano; y así } \\
\text { se dice: tener una cosa IN PRONTU. In promtu } \\
\text { habere. }\end{array}$ & $\begin{array}{l}\text { IN PRONTU. expr. puramente latina que se } \\
\text { aplica á las cosas que están á la mano ó se hacen } \\
\text { de pronto; y así se dice: tener, hacer una cosa IN } \\
\text { PRONTU. In promtu habere. Se usa tambien como } \\
\text { sustantivo. }\end{array}$ \\
\hline $\begin{array}{l}\text { IRROGAR. a. Causar, ocasionar: asi se dice: le } \\
\text { IRROGó un gran perjuicio. }\end{array}$ & $\begin{array}{l}\text { IRROGAR. a. Causar, ocasionar: así se dice: } \\
\text { le IRROGó un gran perjuicio. Se usa tambien } \\
\text { como recíproco. }\end{array}$ \\
\hline $\begin{array}{l}\text { ZARPAR. a. Náut. Levar el áncora. Anchoram } \\
\text { attollere, levare. }\end{array}$ & $\begin{array}{l}\text { ZARPAR. a. Náut. Levar el áncora. Anchoram } \\
\text { attollere, levare. Úsase tambien como neutro } \\
\text { cuando se dice, por ejemplo: ZARPó de tal } \\
\text { puerto la escuadra inglesa. }\end{array}$ \\
\hline
\end{tabular}

\section{CONCLUSIÓN}

La atención al uso en el diccionario académico mediante la incorporación de notas y ejemplos es un tema complejo que se presenta con mucha variedad y una considerable evolución. Se refleja en este tipo de información tanto la evolución de la técnica lexicográfica, con sus mejoras y también con sus asistematicidades, como, con mayor o menor perfección, la evolución del léxico, de sus agrupaciones prototípicas e incluso, en ocasiones, de la consideración normativa de ambos elementos. En este sentido, las notas y ejemplos constituyen una manifestación más de la actualización del diccionario.

El punto de partida ha sido el Diccionario de autoridades, un repertorio que atesora una rica información de uso de muy variado tipo perfectamente integrada en el entramado del discurso lexicográfico. El primer diccionario académico se configura como una obra modelo para el uso lingüístico, que aflora en los diversos tipos de notas, junto a los ejemplos y los textos citados. Esta información experimenta cambios importantes ya desde la segunda edición del Diccionario de autoridades, que mantiene, reescribe y aún acrecienta la información sobre el empleo de las palabras, en especial la información gramatical.

Con la transformación del Diccionario de autoridades al diccionario usual se inicia un trayecto en el que, con la pérdida de los textos, las notas sintagmáticas de uso y los ejemplos quedan en cierta medida exentos, al tiempo que adquieren una función esencial en la contextualización de las unidades léxicas. No parece que existieran unas directrices claras para la inserción de este tipo de anotaciones y, en la práctica, se confirma cierta tendencia a su simplificación y, como consecuencia de ello, al incremento de la heterogeneidad, fruto de procesos de revisión en momentos distintos y, además, parciales y no sistemáticos. La adición de notas y ejemplos y la intervención en las ya existentes se percibe de forma notable en las ediciones de 1780, 1803 y 1817; disminuye sensiblemente en las dos ediciones siguientes, que tienden a suprimir o reducir esa información y a incluir pocos ejemplos y notas en los lemas nuevos, siendo especialmente relevante la tendencia a la supresión en el DRAE 1832; y se va revitalizando lentamente en 1843 y 1852 . Así pues, la evolución del tratamiento de la información sobre el uso entra dentro de la inercia propia del diccionario académico: retoques aquí y allá, y tendencia a la conservación de la información. Buen ejemplo de este comportamiento son los adjetivos relacionales, cuyos ejemplos tienen una larga tradición, llegando alguno de 
ellos hasta la última edición (ley agraria, furor báquico, oda pindárica, principios mecánicos, alfanje moruno); otros, sin embargo, se quedaron por el camino (cfr. epígrafe 4.3).

Se confirma una distinta deriva de la información de uso según su tipo. En general, la información de carácter paradigmático, que aporta variantes formales o sinónimos, tiende a desaparecer o a resolverse en meras remisiones, lo que más que una pérdida de información aporta coherencia y precisión lexicográficas. La información sintagmática que proporcionan las notas de uso y los ejemplos, en cambio, se mantiene, se incorpora o se actualiza, y supone una ampliación de la dimensión gramatical del diccionario, que supera la mera mención de la categoría gramatical del lema. Así, las indicaciones sobre la construcción y el régimen verbal van creciendo, los adjetivos relacionales suelen llevar ejemplos acompañados de un sustantivo, los verbos polisémicos, como dar o hacer, tienen tendencia a ilustrar y diferenciar las acepciones por medio de ejemplos, etc.

En las diez primeras ediciones del diccionario usual no se producen novedades importantes en la forma de introducir las notas que aportan información sintagmática y los ejemplos de uso; continúa, pues, con pequeñas modificaciones, el amplio elenco de fórmulas empleadas en Autoridades (se usa, así se dice, como...). Por otra parte, los frecuentes cambios tipográficos y de puntuación, nunca uniformes, de unas ediciones a otras manifiestan cierta tendencia a delimitar en el artículo la información sobre el uso para separarla de la definición, y contribuyen a la formalización de la entrada lexicográfica. No será hasta la segunda mitad del siglo XIX, periodo en el que las tareas lexicográficas de la Academia se intensifican de manera notable, cuando se produzcan importantes variaciones en el discurso lexicográfico. Las ediciones de 1869, 1884 y 1899 supondrán una amplia revisión de la nomenclatura de la obra y también de la microestructura, además de producirse un importante avance en la metodología lexicográfica (Clavería, 2016: 132-133). Esta evolución también se dejará ver en las notas y los ejemplos de uso, cuya presentación se ajustará a unos moldes formales fijos que proporcionarán uniformidad al diccionario y un refinamiento de la técnica lexicográfica.

\section{REFERENCIAS BIBLIOGRÁFICAS}

Alvar Ezquerra, M. (2005). La lexicografia monolingüe del siglo XVIII. https://books.google.es/bo oks?id=DMyNJIyMtWUC\&pg=PA8\&lpg=PA $8 \& \mathrm{dq}=$ cambios + Segund $\# \mathrm{v}=$ onepage $\& \mathrm{q} \& \mathrm{f}=$ false [consulta realizada el 29 de noviembre del 2018].

Álvarez de Miranda, P. (2000). "La lexicografía académica de los siglos XVIII y XIX". En Ahumada, I. (coord.). Cinco siglos de lexicografía del español: IV Seminario de lexicografía hispánica. Jaén: Universidad de Jaén, pp. 35-61.

Álvarez de Miranda, P. (2005). "La proeza de un diccionario con textos. Algo más sobre el Diccionario de Autoridades". En Martínez Romero, T. (ed.). Les lletres hispaniques als segles XVI, XVII $i$ XVIII. Castellón: Universitat Jaume I / Fundació Germà, pp. 74-92.

Atkins, B. T. S. y M. Rundell (2008). The Oxford Guide to Practical Lexicography. Oxford: University Press.

Azorín, D. (2018). "El léxico con marcación estilística”. En Clavería, G. y M. Freixas (coords.). El diccionario de la Academia en el siglo XIX: la quinta edición (1817) al microscopio. Madrid: Arco/Libros, pp. 427-458.

Blanco, M. A. (2018a). "El contexto del diccionario: los códigos académicos vigentes en 1817". En Clavería, G. y M. Freixas (coords.). El diccionario de la Academia en el siglo XIX: la quinta edición (1817) al microscopio. Madrid: Arco/Libros, pp. 57-63. 
Blanco, M. a A. (2018b). "Un proceso significativo de revisión: la definición de las letras". En Clavería, G. y M. Freixas (coords.). El diccionario de la Academia en el siglo XIX: la quinta edición (1817) al microscopio. Madrid: Arco/Libros, pp. 175-202.

Blecua, J. M. (2006). Principios del Diccionario de autoridades. Discurso leído el día 25 de junio de 2006 en su recepción pública en la Real Academia Española. Madrid: Real Academia Española.

Buenafuentes, C. (2018). "Los criterios de lematización: las formas complejas". En Clavería, G. y M. Freixas (coords.). El diccionario de la Academia en el siglo XIX: la quinta edición (1817) al microscopio. Madrid: Arco/Libros, pp. 115-136.

Clavería, G. (2016). De vacunar a dictaminar: la lexicografía académica decimonónica y el neologismo. Madrid-Frankfurt: Iberoamericana-Vervuert.

Clavería, G. (en prensa, 2020). "El Diccionario de la lengua castellana (1817-1832) y la propuesta decimonónica de diccionario manual", Boletín de la Real Academia Española, tomo 100, cuaderno 322.

Clavería, G. (en prensa). "América en el Diccionario de la lengua castellana de la Real Academia Española (1817-1852)". Actas del XI Congreso Internacional de Historia de la Lengua Española (Lima, 6-10 agosto 2018).

Clavería, G. y Freixas, M. (coords.) (2018). El diccionario de la Academia en el siglo XIX: la 5. ${ }^{a}$ edición (1817) al microscopio. Madrid: Arco/Libros.

Dubois, J. y C. Dubois (1971). Introduction à la lexicographie: le dictionnaire. París: Larousse, 90-98.

Freixas, M. (2010). Planta y método del Diccionario de autoridades. Orígenes del método lexicográfico de la Real Academia Española (1713-1739). A Coruña: Universidade da Coruña.

Freixas, M. (2018). "La definición y la descripción". En Clavería, G. y M. Freixas (coords.). El diccionario de la Academia en el siglo XIX: la quinta edición (1817) al microscopio. Madrid: Arco/ Libros, pp. 139-173.

Garrido Moraga, A. M. (1987). "Un episodio en la lexicografía académica del siglo XVIII: las incorporaciones de la segunda impresión del diccionario", Lingüística Española Actual, 9/2, pp. 199-206.

Garrido Moraga, A. M. (1992). "Un episodio en la lexicografía académica del XVIII. Las supresiones en la segunda impresión del diccionario", RILCE: Revista de Filología Hispánica, 8/2, pp. 265-285.

Garriga, C. (2002). "Del tratamiento del ejemplo en gramáticas y diccionarios". En Veiga, A. et alii (eds.). Léxico y gramática. Lugo: Tris Tram, pp. 131-146.

Garriga, C. (2018). "Las voces de la química". En Clavería, G. y M. Freixas (coords.). El diccionario de la Academia en el siglo XIX: la quinta edición (1817) al microscopio. Madrid: Arco/Libros, pp. 313-337.

Gómez de Enterría, J. (2018). "Las voces de ciencias naturales y áreas afines". En Clavería, G. y M. Freixas (coords.). El diccionario de la Academia en el siglo XIX: la quinta edición (1817) al microscopio. Madrid: Arco/Libros, pp. 275-311.

Haensch, G. y C. Omeñaca (2004). Los diccionarios del español en el siglo XXI, 2. a edición corregida y aumentada. Salamanca: Ediciones Universidad.

Jiménez Ríos, E. (2018a). "Cambio de orientación en la lexicografía de la Real Academia Española a propósito de los arcaísmos en el DRAE de 1822”, Orillas, Rivista d'Ispanistica, 7, pp. 309-328.

Jiménez Ríos, E. (2018b). "El diccionario, fuente para la historia del léxico: la supresión de arcaísmos gráficos en la sexta edición del Diccionario de la lengua castellana de la Real Academia Española (1822)", Boletín de Filología de la Universidad de Chile (BFUCh), LIII/1, pp. 131-168.

Jiménez Ríos, E. (2018c). "El léxico con marcación diacrónica". En Clavería, G. y M. Freixas (coords.). El diccionario de la Academia en el siglo XIX: la quinta edición (1817) al microscopio. Madrid: Arco/Libros, pp. 399-426.

Jiménez Ríos, E. (2019). "Participio pasivo y arcaísmo en el DRAE (ediciones de 1822-1832)”, ELUA, anexo V.

Lara, L. F. (1992). "El discurso en el diccionario". En G. Wotjak (ed.). Estudios de lexicología y metalexicografía del español actual. Tubinga: Max Niemeyer, pp. 1-12. 
Lara, L. F. (1997). Teoría del diccionario monolingüe. México: El Colegio de México.

Martin, R. (1989). "L'exemple lexicographique dans le dictionnaire monolingue". En Hausmann, F. J. et alii. Wörterbücher. Ein internationales Handbuch zur Lexikographie. Berlin-New York: Walter de Gruyter, vol. I, pp. 599-607.

Muñoz, L. (2018). "La sinonimia y las remisiones". En Clavería, G. y M. Freixas (coords.). El diccionario de la Academia en el siglo XIX: la quinta edición (1817) al microscopio. Madrid: Arco/ Libros, pp. 203-221.

NTLLE = Real Academia Española (2001). Nuevo tesoro lexicográfico de la lengua española, edición en DVD. Madrid: Espasa. [También en <http://ntlle.rae.es>].

Pascual Fernández, M. ${ }^{a}$ L. (2009). El sistema de abreviaturas en el diccionario académico: Introducción (1726), institucionalización (1770) y consolidación (1780). La marcación del léxico especifico. Bellaterra: Universitat Autònoma de Barcelona. [Trabajo de investigación disponible en http:// dfe.uab.es/neolcyt/images/stories/estudios/lexicografia/pas2009.pdf].

Pascual Fernández, M. ${ }^{\mathrm{a}}$ L. (2012). "Los ejemplos en las voces de especialidad: DRAE (1780), 1. ${ }^{\mathrm{a}}$ edición". En Nomdedeu, A. et alii (coords.). Avances de lexicografía hispánica. Tarragona: Universitat Rovira i Virgili, vol. II, pp. 415-428.

Pascual Fernández, M. ${ }^{a}$ L. (2013). Diccionario de autoridades (2. ${ }^{\mathrm{a}}$ ed.): técnica lexicográfica y lengua de la ciencia, tesis doctoral. Bellaterra: Universitat Autònoma de Barcelona, disponible en $<\mathrm{http}: / /$ ddd.uab.cat/record/115331>.

Pascual Fernández, M. ${ }^{a}$ L. (2019). "Remisiones con lo mismo que, un ensayo en la gestación del diccionario académico". En Arnal, M. ${ }^{\mathrm{a}}$ L. et alii (eds.). Actas del X Congreso Internacional de Historia de la Lengua Española, Zaragoza: Institución "Fernando el Católico", vol. II, pp. 1161-1272.

Paz, A. (2018). "La información lexicográfica de las formas complejas". En Clavería, G. y M. Freixas (coords.). El diccionario de la Academia en el siglo XIX: la quinta edición (1817) al microscopio. Madrid: Arco/Libros, pp. 223-252.

Quemada, B. (1968). Les dictionnaires du Français moderne 1539-1863. Paris: Didier, pp. 505-560.

Rey, A. (1995). "Du discours au discours par l'usage: pour une problématique de l'exemple", Langue française, 106, pp. 95-123.

Rey-Debove, J. (1971). Étude linguistique et sémiotique des dictionnaires français contemporains. La Haye-Paris: Mouton.

Rey-Debove, J. (1992). "Les domaines respectifs de l'exemple et de la citation dans les dictionnaires de langue actuels". En García, C. et alii (eds.). Simposio de lexicografía actual: elaboración de diccionarios. A Coruña: Real Academia Galega, pp. 39-47.

Rivera, M. ${ }^{a}$ del R. (2009). "Las etimologías perdidas de la Academia (1780-1803): ¿descuidos o inquietudes encubiertas?”, Revista de Historia de la Lengua Española, 4, pp. 63-77.

Ruhstaller, S. (2003). "Las obras lexicográficas de la Academia". En Medina, A. M. (coord.). Lexicografía española. Barcelona: Ariel, pp. 235-261.

Seco, M. (1991 [2003])). "Introducción" del Diccionario de la lengua castellana reducido a un tomo para su más fácil uso. Facsímil de la primera edición (1780). Madrid: Espasa-Calpe, pp. v-xii [citado por Estudios de lexicografía española, segunda edición aumentada. Madrid: Gredos, pp. 237-258].

Terrón, N. (2018). "La regularización ortográfica". En Clavería, G. y M. Freixas (coords.). El diccionario de la Academia en el siglo XIX: la quinta edición (1817) al microscopio. Madrid: Arco/ Libros, pp. 67-91.

Zgusta, L. (1971). Manual of Lexicography. Mouton: Prague. 